Dear Author:

This file contains the proofs of your article scheduled to appear in a forthcoming issue of THE REVIEW OF ECONOMICS AND STATISTICS.

Please print these proofs and check them for accuracy. In addition:

- Proofread tables and equations carefully

- Check that any Greek characters appear correctly

If you find query call-outs in the margins, refer to the final page of your proof where you will find queries regarding your article. Please answer all queries.

Kindly limit your changes to those necessary to correct errors or inconsistencies. Mark any corrections in pen or colored pencil directly on the proofs.

Within three days of receipt, please return your corrected proof to me. Since time is of the essence, please use an overnight delivery service.

If you prefer, you may send your corrections to me via fax at 617-812-6363 or email at ewitz@mit.edu. If you send a fax, please make sure that all changes are printed legibly in black pen. If you send an email, please make sure that all of your changes are clearly identified by page, paragraph, and line number.

In order for your changes to be incorporated it is essential that your corrected proofs are received by the MIT Press no later than three days from the day you received them.

Please note that you may order reprints of your article by going to the MIT Press Journals reprint ordering site: www.sheridan.com/MITpress/eoc. There is no deadline for ordering, and you may use this system to order additional reprints at any time. If the system is not yet ready to accept orders for a current issue, please use the email reminder function. You are the only one receiving this letter; please coordinate with your co-authors.

Thank you in advance for your cooperation.

Yours sincerely,

Eric Witz

Senior Production Editor

MIT Press Journals

One Rogers Street

Cambridge, MA 02142-1209

(p) 617-258-0586

(f) $617-812-6363$

ewitz@mit.edu 


\title{
HETEROGENEOUS GOVERNMENT SPENDING MULTIPLIERS IN THE ERA SURROUNDING THE GREAT RECESSION
}

\author{
Marco Bernardini, Selien De Schryder, and Gert Peersman*
}

\begin{abstract}
We use novel quarterly data of U.S. states to examine the dynamics of relative spending multipliers in the decade surrounding the Great Recession. While multipliers were around 1 in expansions, they reached values above 4 when a state was in a recession. Also a high (low) degree of household indebtedness augmented (lowered) a state's multiplier by 0.5 in expansions and 2 in recessions. We further document modest positive spillover effects across states and show that a mere redistribution of spending across states also had a significant influence on the aggregate U.S. economy due to cross-state heterogeneity of the effects.
\end{abstract}

\section{Introduction}

$\mathrm{T}$ HE impact of changes in government expenditures on economic activity has been a central question of macroeconomic research for many years. In this context, an increasing number of studies have used state-level panel data to estimate the effects of government purchases on local activity-so-called relative or local fiscal multipliers (Nakamura \& Steinsson, 2014; Shoag, 2013; Brückner \& Tuladhar, 2014; Serrato \& Wingender, 2016; Dupor \& Guerrero, 2017). An advantage of this approach is that disaggregate data augment the number of observations and variation in the data substantially, which could increase the precision of the estimates. A drawback is that the results are not representative for the aggregate effects. In essence, these studies estimate relative multipliers across regions, holding national effects of fiscal policy constant (Ramey, 2011b).

Relative fiscal multipliers are nevertheless important in their own right. In particular, a better understanding of relative multipliers is necessary for policymakers since business cycle fluctuations could be highly diverse across regions and states. For example, annual real GDP growth in Michigan and Arizona collapsed by respectively $-8.1 \%$ and $-8.2 \%$ in 2009. At the same time, New York and Alaska recorded positive growth rates of $2.1 \%$ and $9.1 \%$, respectively. In a currency union, local fiscal policy and redistribution of resources across subnational entities are among the few remaining policy tools for stabilizing local business cycles and smoothing asymmetric shocks.

Notwithstanding their relevance, existing studies on relative multipliers are of only limited use for policymakers in practice. Specifically, such multipliers have so far been estimated with annual or lower-frequency data. Given that there are implementation lags for fiscal policy and recessions typ-

Received for publication June 14, 2017. Revision accepted for publication January 7, 2019. Editor: Yuriy Gorodnichenko.

*Bernardini: Bank of Italy; De Schryder and Peersman: Ghent University. We acknowledge financial support from the Research Foundation Flanders (FWO) and Ghent University's Special Research Fund. All remaining errors are ours. The views expressed in this paper are our own and do not necessarily reflect those of the Bank of Italy or the Eurosystem.

A supplemental appendix is available online at http://www.mitpress journals.org/doi/suppl/10.1162/rest_a_00830. ically last less than one year, it is not clear whether and how these annual multipliers are informative for dampening local economic fluctuations. Furthermore, due to the annual frequency of state-level data, state relative multipliers are typically estimated over very long sample periods (e.g., 1966 to 2006 in Nakamura \& Steinsson, 2014; 1951 to 2014 in Dupor \& Guerrero, 2017). In the meantime, however, it is well known that fiscal multipliers are not structural constants and may depend on various features of the economy that vary over time and across states (Hall, 2009). Auerbach and Gorodnichenko (2012a, 2012b) have, for example, documented that increases of national government purchases are much more effective in recessions than expansions, while Bernardini and Peersman (2018) find considerably larger aggregate multipliers in periods of private debt overhang. Similarly, Nakamura and Steinsson (2014) find larger relative multipliers in highunemployment periods, whereas a recent study of Demyanyk, Loutskina, and Murphy (2017) identify larger relative multipliers in core-based statistical area (CBSA) geographies with higher consumer debt. These findings also receive ample theoretical support (Michaillat, 2014; Canzoneri et al., 2016; Eggertsson \& Krugman, 2012; Andrés, Boscá, \& Ferri, 2015). Relative multipliers for individual states at a specific moment in time may hence substantially diverge from the average tendency. Accordingly, average relative multipliers are probably not very helpful for policymakers in real time, such as in the midst of the recent financial crisis. Finally, average relative multipliers are not useful to assess the national benefits of mere redistributions of government spending across regions; the aggregate effects of such policies on economic activity are by construction neutral.

In this study, we try to fill several of these gaps. More precisely, using a novel quarterly data set of U.S. states over the sample period 2005Q1 to 2015Q4, we estimate state relative government spending multipliers and the key determinants of the multipliers in the era surrounding the Great Recession with instrumental variables panel local projection methods in the spirit of Ramey and Zubairy (2018). This period is particularly interesting given the policy and academic debates on the question whether the effects of fiscal policy were different than in normal times (Eggertsson \& Krugman, 2012; Blanchard \& Leigh, 2013; Ramey \& Zubairy, 2018) and the fact that this episode has been characterized by a substantial implicit relocation of government resources across states. ${ }^{1}$ The data set is entirely based on publicly available

\footnotetext{
${ }^{1}$ For example, Chodorow-Reich et al. (2012) document that the level of federal money received by states in the context of the ARRA's Medicaid match program between 2009 and June 2010 varied between $\$ 103$ per person aged 16 or older in Utah and \$507 in Washington, DC, with an interquartile range of $\$ 114$.
} 
information that has recently been released. Specifically, we use the Regional Economic Accounts database of the Bureau of Economic Analysis (BEA) to obtain state-level GDP and government value added at a quarterly frequency, and the Consumer Credit Panel data set of the Federal Reserve Bank of New York (FRBNY) to collect state-level household debt series.

These data sources have several advantages to tackle the issues. First, they allow us to estimate relative government spending multipliers at a quarterly frequency and analyze the macroeconomic dynamics at different horizons following the fiscal policy impulse. Second, due to the large number of observations compared to annual data sets, the multipliers can be estimated over shorter periods and still have accurate estimates. We demonstrate that this is at least the case for the period surrounding the Great Recession, which has been an era with substantial variation in government spending. Third, the data set allows us to investigate the role of several potential determinants for the size and dynamics of relative multipliers. In particular, we examine the influence of spillover effects across states and assess whether relative multipliers in this period depended on the stance of the business cycle or the amount of private debt, or the interaction of both conditions at the state level. Since business cycles and household debt have varied substantially across states during this period, there is again a lot of heterogeneity in the data that can be exploited to pin down their influence on multipliers. Finally, a quarterly data set for state-specific government value added and GDP allows us to apply the popular Blanchard and Perotti (2002) approach to directly identify exogenous shocks to government expenditures rather than relying on indirect methods such as the Bartik (1991) instrument approach. In sum, the results of our quarterly estimations should provide useful insights for fiscal policymakers and the stabilization of state business cycles, as well as a better understanding of the dynamics and determinants of multipliers. The latter is, in turn, helpful to assess the national consequences of fiscal redistribution policies.

The estimations reveal several new insights about relative multipliers. First, state multipliers were on average quite similar to those that have been reported for the decades preceding the crisis (e.g., Nakamura \& Steinsson, 2014). We find a benchmark average cumultative multiplier of approximately 1.3 in the impact quarter. Government spending is thus a powerful tool for a relatively swift stabilization of local business cycles. The size of average multipliers also appears to be stable at longer horizons, while we find moderate positive spillover effects on other states-in particular, trade partners.

Furthermore, we find substantial heterogeneity in the magnitude and the dynamics of relative multipliers across states and over time. Specifically, relative multipliers turned out to be larger, reaching values around 2 when a state was in a recession at the moment of the shift in government expenditures and even above 4 in deep recessions. Multipliers also appear to be more persistent in recessions than expansions. In addition, the magnitude of the multiplier was significantly influenced by the state's private indebtedness. A 1 standard deviation higher (lower) household debt-to-income ratio was associated with an increase (decline) of the state's multiplier by approximately 0.5 in expansions and up to 2 when the state was in a recession. These findings suggest that the business cycle and degree of private indebtedness of U.S. states are key drivers of relative multipliers and should be taken into account when designing fiscal policies at regional levels.

Can we learn something about the aggregate effects of fiscal redistribution policies? The results suggest that redistribution of government expenditures from a state with a growing economy or low household debt levels to states that are in a recession or have relatively high household debt ratios, and hence larger relative multipliers, should stimulate aggregate economic activity. To test this conjecture more directly, we construct a simple indicator that proxies changes in the regional distribution of aggregate U.S. government spending toward states in a recession or states with high household debt ratios. We then estimate the macroeconomic effects of innovations to this indicator, controlling for changes in aggregate government expenditures. We find that shifts in the distribution of spending toward states that are potentially more sensitive to fiscal policy indeed had a significant positive effect on aggregate U.S. real GDP. These results indicate that mere targeted redistributions of government expenditures across states can be beneficial for the aggregate economy as well.

The rest of the paper is organized as follows. In section II, we describe our quarterly data set, present the results for the average (linear) state relative multipliers in the period surrounding the Great Recession, and evaluate spillover effects across states. Section III examines the underlying drivers of state multipliers, while section IV analyzes whether a simple redistribution of government spending across states could also influence the aggregate economy. Section V concludes.

\section{Average Relative Multipliers}

\section{A. Quarterly State-Level Data Set}

The analysis in this paper is based on a novel quarterly panel data set at the level of U.S. states, covering the fifty states and the District of Colombia. The data set draws entirely from publicly available and recently released time series for the individual states. We use the Regional Economic Accounts (REA) of the BEA to collect state-level quarterly data on GDP and its main components. The sample period, based on data availability, is 2005Q1 to 2015Q4, which allows us to estimate the dynamics of relative government spending multipliers across states during the period surrounding the Great Recession. This is an era that receives a lot of attention in the fiscal policy literature. For example, Blanchard and Leigh (2013) have shown that aggregate government spending multipliers were much larger during the Great Recession than in normal times. In section III, we merge the data with household debt information obtained from the 

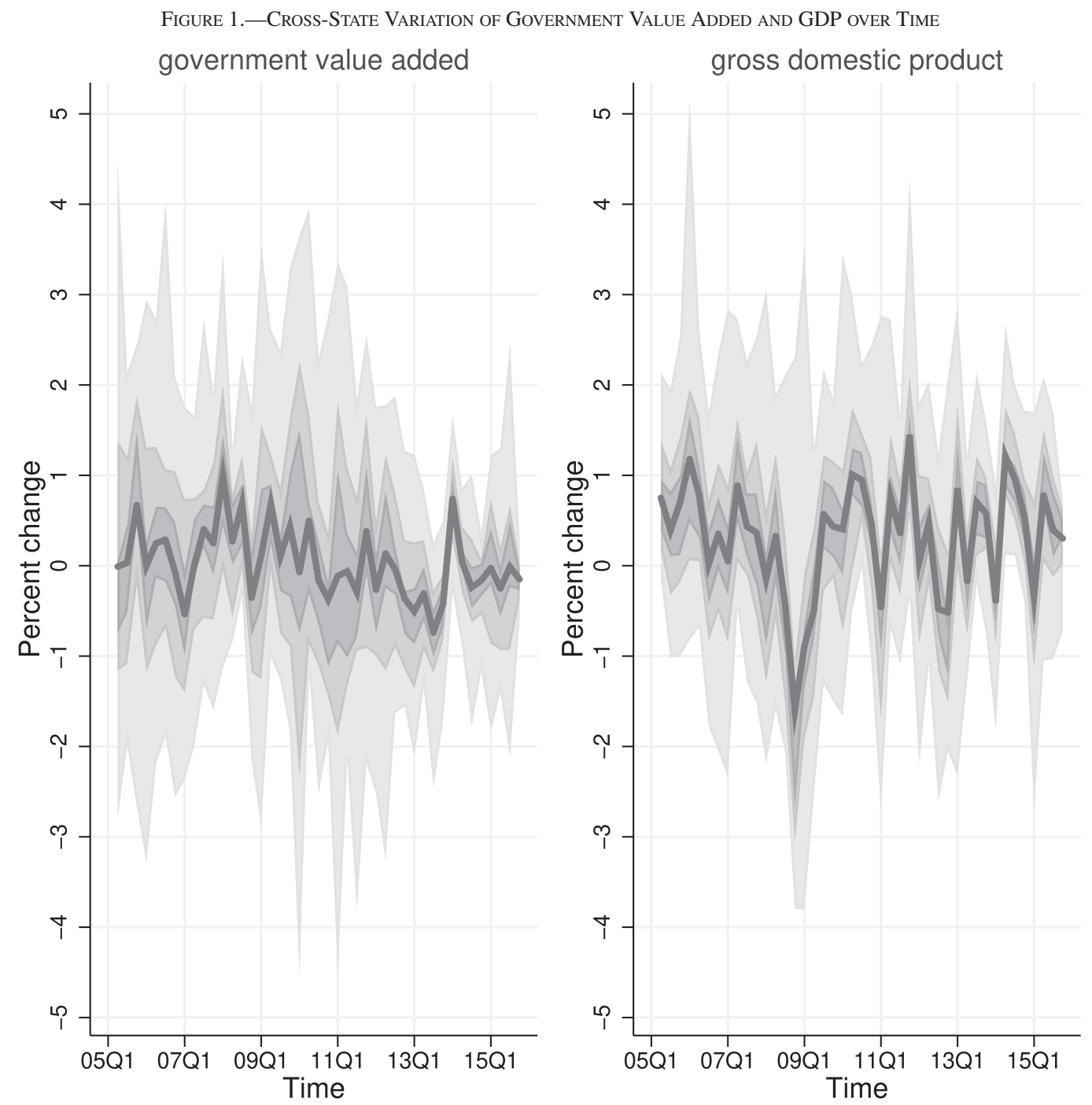

The green lines show the cross-state averages of the quarterly growth rates of real government value added and real GDP over time. The bands show different percentile intervals: 35 th-65th (30\%), 20th-80th (60\%), and 5th-95th $(90 \%)$.

Consumer Credit Panel (CCP) of the FRBNY to examine the determinants of the multipliers during this period. ${ }^{2}$

The variables from the REA that will be used to estimate government spending multipliers are state-level government value added and gross domestic product. Notice that statelevel government value added comprises compensation of government employees and consumption of government capital. Examples are education, policy, and military personnel services. Government value added is a subcomponent of government purchases that also includes government purchases of goods from the private sector, such as aircraft carriers or tanks. ${ }^{3}$ The advantage of this component is that it implies that

\footnotetext{
${ }^{2}$ The REA-BEA quarterly state-level data were officially released in December 2015, and the CCP-FRBNY data were publicly released in December 2016. See the data appendix for detailed information on the exact sources of the data. We are not aware of studies that have used the REA-BEA data yet. The CCP-FRBNY data have been used by Albuquerque (2017) to study the role of monetary policy for household debt cycles.

${ }^{3}$ See Ramey (2013) for a detailed explanation and discussion of this aggregate.
}

government production and the government spending shocks that we will identify effectively took place in the state and not elsewhere, while all other production in the state is carried out by the private sector. State-level GDP covers the total contribution of private and public sectors to overall GDP and can be seen as the state counterpart of national GDP. Another advantage is that the REA data contain both nominal and real series for each state. Hence, we do not have to use national (aggregate) price indexes or construct regional inflation measures to deflate nominal variables. ${ }^{4}$

Figure 1 depicts the evolution of the cross-sectional averages of both real aggregates over time, whereas the shaded gray areas represent respectively the 35 th to 65 th (dark gray),

\footnotetext{
${ }^{4}$ In the estimations, we use the real series of both variables directly. Hence, in contrast to some other studies, we do not use the GDP deflator to deflate government value added. The reason is that the GDP deflator of several oilproducing states is characterized by large swings that are the consequence of oil price fluctuations, which would result in implausible shifts of real government value added.
} 
the 20th to 80th, and the 5th to 95th percentiles (light gray) of the individual states. Besides nonnegligible average volatility over time, the graphs reveal considerable cross-state heterogeneity in the signs and magnitudes of the changes in both aggregates within the sample period. In addition to the quarterly frequency, the large extent of variation coming from the use of disaggregate data is a key advantage of our data set to obtain precise and reliable relative spending multipliers for this period.

\section{B. Methodology}

We examine the dynamics of the cumulative government spending multiplier, which is the ratio of the cumulative changes in GDP and government spending at time $t+h$ induced by a government spending shock at time $t$. By taking into account the entire volume of government spending between $t$ and $t+h$ induced by the initial shock, this indicator is a fair measure of the medium-run effects of fiscal shocks on economic activity. Following Ramey (2016), we directly estimate the cumulative multiplier over a two-year horizon $(H=8)$ using an instrumental variables model based on Jorda's (2005) local projections method:

$$
\sum_{l=0}^{h} \tilde{y}_{i t+l}=\beta_{h}\left(\sum_{l=0}^{h} \tilde{g}_{i t+l}\right)+\gamma_{h}(L) c \tilde{t} r_{i t}+\alpha_{i h}+\delta_{t h}+\varepsilon_{i t+h}
$$

For $h=0, \ldots, H$, the cumulative path of GDP $\sum_{l=0}^{h} \tilde{y}_{i t+l}$ in a U.S. state $i$ between $t$ and $t+h$ is regressed on the cumulative path of government spending $\sum_{l=0}^{h} \tilde{g}_{i t+l}$, which is instrumented by a government spending shock that we discuss below. $c \tilde{t} r_{i t}$ is a set of predetermined control variables that includes four lags of state-level government production and state-level GDP, while $\alpha_{i h}$ and $\delta_{t h}$ are state-specific and time-specific effects, respectively. $\varepsilon_{i t+h}$ captures the residual variation. The regression of equation (1) provides a direct estimate of the cumulative multiplier at each horizon, $\beta_{h}$, and its statistical uncertainty. Furthermore, fixed effects allow us to control for state-specific features that are constant over time (e.g., institutional or structural characteristics), while time effects control for aggregate shocks and common policies such as changes in monetary policy, aggregate taxes, and national government spending. The use of time effects implies that we estimate relative state multipliers, which should be interpreted as the effects of an increase in government expenditures in one state relative to another on relative output (Nakamura \& Steinsson, 2014). Relative multipliers are thus conceptually different from aggregate multipliers.

As Hall (2009) suggested, we express the variables in the model as follows:

$$
\tilde{v}_{i t+l}=\frac{\Delta_{l+1} v_{i t+l}}{y_{i t-1}^{*}},
$$

where $v_{i t}$ is a generic income variable in real terms and $y_{i t-1}^{*}$ is lagged potential output. ${ }^{5}$ This specification guarantees that government spending and GDP are in the same units, which allows us to interpret $\beta_{h}$ as a multiplier (i.e., not as an elasticity). The use of an ex ante transformation not only provides a direct estimate of the multiplier, it also minimizes the potential bias associated with the alternative ex post conversion of the estimated elasticity in a multiplier. As Ramey and Zubairy (2018), noted ex post transformations are sensible only when the level of government spending as a share of GDP $(G / Y)$ is fairly constant in the sample. Similar to the case of time series models using historical data, which have to deal with a considerable increase in the share of government spending around World War II, panel models using disaggregate U.S. data have to deal with the fact that the share might be highly different across states. In our sample, the spending shares indeed range between $9 \%$ and $37 \%$, with a cross-sectional average of $14 \%$.

An advantage of the quarterly frequency of the state-level data set is that it allows us to apply the popular Blanchard and Perotti (2002) approach to identify exogenous government spending shocks. This method exploits the timing assumption that due to the presence of political and institutional delays, the amount of government expenditures is predetermined and cannot react instantaneously to macroeconomic shocks. For quarterly data and government value added, this assumption is plausible. Most states, for example, have an annual appropriation process for their budgets, even though with the option of midyear revisions in case of expected shortfalls. The relative government spending shocks can be obtained by estimating state-level rules for government value added, where government value added in an individual state is assumed to depend on a set of predetermined variables $c t r_{i t}$, state-specific and time-specific effects, and an autonomous shock $\left(\right.$ shock $\left._{i t}\right)$ :

$$
\tilde{g}_{i t}=\kappa(L) c \tilde{t} r_{i t}+\alpha_{i}+\delta_{t}+\text { shock }_{i t} .
$$

Similar to equation (1), the set of predetermined variables in equation (2) has four lags of state-level government value added and GDP. The residuals of state-level rules for government value added are more precise measures of local government spending than instruments based on the oftenapplied Bartik (1991) allocation approach, which measures local spending shocks as national changes in, say, military spending scaled by a state-specific scaling factor. ${ }^{6}$ In contrast to national (military) spending that is distributed across states or mere transfers from the federal government to the regions, a drawback of state-level government value added

\footnotetext{
${ }^{5} \Delta_{l+1} v_{i t+l}=v_{i t+l}-v_{i t-1}$. Potential output is defined as the HodrickPrescott filtered trend of state-level GDP with $\lambda$ set to $1 e+06$. An alternative data transformation to obtain direct multiplier estimates is the one used by Gordon and Krenn (2010). As documented by Ramey and Zubairy (2018), for example, results are typically very similar.

${ }^{6}$ For example, Dupor and Guerrero (2017) use the ratio of a state's share of national spending divided by the state's share of national income as a scaling factor to obtain an instrument for local shocks.
} 
is that the expenditures are funded by the federal as well as the state budget, which implies that local taxes do not necessarily remain constant in response to the shocks. In section IID, we assess the robustness of the results for a specification that relies on scaled federal spending shocks. Notice also that a caveat of the Blanchard and Perotti (2002) method is that the shocks may be anticipated by the private sector. Ramey (2011a) has shown that this is the case for the United States at the aggregate (national) level.

We estimate equations (1) and (2) using the fixed-effects estimator, which allows for heterogeneous constants across states but assumes homogeneous slope coefficients. As a sensitivity check, in section IID, also report the results of a mean group estimation that allows for heterogeneous slopes. The standard errors in all the estimations are based on the Driscoll and Kraay (1998) correction, which takes into account the potential residual correlation across U.S. states, as well as serial correlation and heteroskedasticity among the residuals over time. The standard errors of the multiplier are further adjusted in order to take into account the uncertainty related to the first stage regression. To allow for a comparison of the estimates across horizons $h$, we hold the sample constant (we use the sample for the longest horizon, $H=8$ ), leaving us with a balanced macropanel consisting of 1,581 observations.

\section{Estimation Results}

The benchmark results are shown in figure 2. The green solid line represents the size of the cumulative relative multiplier $\beta_{h}$ over a horizon of eight quarters. The dark and light shadings are the $68 \%$ and $90 \%$ Driscoll-Kraay adjusted confidence bands, respectively. The panels of figure 2 show the cumulative multiplier, as well as the impulse responses of government spending and real GDP. The top-right panel displays the Kleibergen-Paap $F$-statistic for weak instruments, which is equivalent to the Montiel-Olea-Pflueger statistic in case of a just-identified specification. ${ }^{7}$ Overall, the multipliers are estimated with good precision, and the instrumental regressions are well identified.

Although it is difficult to compare our quarterly cumulative spending multipliers with other studies, a first interesting observation is that state relative multipliers during the decade surrounding the Great Recession were on average not very different from those reported in the literature for the decades before the financial crisis. We obtain a relative multiplier, which is on average 1.3 during the first year and 1.2 during the first two years. As a benchmark, Nakamura and Steinsson (2014) regress two-year changes in output on two-year changes in spending and find relative multipliers that range between 1.3 and 1.9 for the period 1966 to 2006 depending

\footnotetext{
${ }^{7}$ The statistics test the null hypothesis that the TSLS bias exceeds $10 \%$ of the OLS bias. In the presence of heteroskedasticity and autocorrelation, the threshold is 19.7 for the $10 \%$ critical value and 23.1 for the $5 \%$ critical value (Montiel Olea, \& Pflueger, 2013). Note that we impose an upper bound (dashed line) in the figure since the statistic is infinite on impact.
}

on the model specification. Serrato and Wingender (2016) report values in the range of 1.7 and 2.2 based on an analysis of U.S. counties and four-year intervals during the $1980 \mathrm{~s}$, 1990s, and 2000s. Furthermore, Shoag (2013) and Demyanyk et al. (2017) present an estimate of 1.4 and 1.5 for the fiscal multiplier in U.S. states for post-2000 samples.

In contrast to studies using regional annual or lowerfrequency data, the quarterly frequency of our data series can shed light on the within-year dynamics of cumulative multipliers. The impact multiplier is 1.3. This implies a $\$ 0.3$ increase (decrease) in relative private sector production for every $\$ 1.00$ increase (decrease) in relative government production. State government spending thus has an instantaneous and sizable impact on local economic activity, making it a powerful tool for a relatively rapid stabilization of local business cycles. The size of the cumulative multiplier also appears to be rather stable at longer horizons (the point estimate ranges between 1.1 and 1.3 during the two years), which suggests that fiscal policy may also be efficient to smooth asymmetric evolutions in states' business cycles in the medium run. A closer look at the impulse responses of government value added and GDP reveals that the shocks in the sample have been characterized by a persistent rise in government value added, resulting in a persistent increase of real GDP, which explains the stability of the multiplier at longer horizons.

\section{Sensitivity of Benchmark Multipliers}

As discussed in section IIB, a caveat of the baseline cumulative multipliers is that government value added is a combination of state- and federal-funded government expenditures. In particular, the former may be associated with changes in local taxes or debt, which could influence the size of the multiplier. In contrast to the national accounts data of the BEA, a limitation of the REA data set is that such a decomposition is not available for individual states; only total government value added is reported for each state. As a robustness check, we therefore also use an instrumental variable (IV) approach that explores differences in the responsiveness of state-level government value added to national government value added funded by the federal government (federal government value added) to identify state-level spending shocks. The approach is partly borrowed from Nakamura and Steinsson (2014) and intrinsically similar to the Bartik (1991) method. ${ }^{8}$ More specifically, in a first step, we isolate the autonomous variation in federal government value added using an aggregate policy rule that is similar to equation (2):

$$
\tilde{g}_{t}^{n a t}=\varphi(L) c \tilde{t}_{t}^{\text {nat }}+\operatorname{shock} k_{t}^{\text {nat }} .
$$

\footnotetext{
${ }^{8}$ In their baseline approach, Nakamura and Steinsson (2014) first regress changes in state military procurement on fixed effects and changes in aggregate military procurement, allowing for different sensitivities across states. The fitted values are then used as an instrument for changes in state spending.
} 
Figure 2.-Average Relative Government SPEnding Multipliers
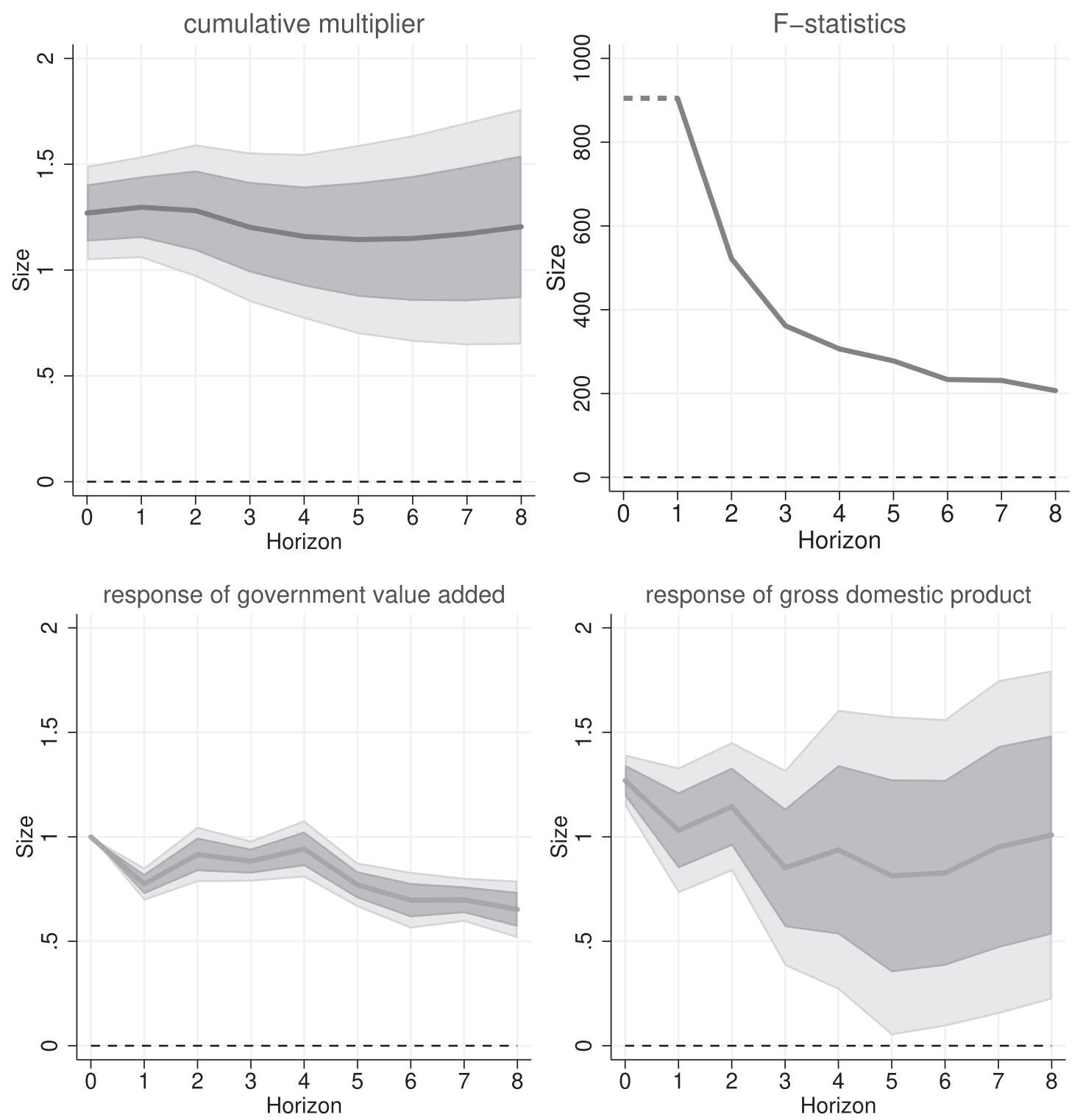

The top panel shows the cumulative relative fiscal multiplier and the related $F$-statistics over a two-year horizon. The dashed part of the blue line represents the imposed upper bound on impact since the $F$-statistic is then infinite. The bottom panel shows the underlying impulse responses of government value added and gross domestic product. Bands are $68 \%$ (dark) and $90 \%$ (light) confidence intervals.

In the next step, we regress changes in state-level government value added on the federal government spending shock, allowing for a heterogeneous impact of the national shock across states and state-specific constants:

$$
\tilde{g}_{i t}=\alpha_{i}+\theta_{i} \text { shock }_{t}^{\text {nat }}+\mu_{i t} .
$$

This yields scaled federal spending shocks for each state $\left(\theta_{i}\right.$ shock $\left._{t}^{\text {nat }}\right)$ that can be used to estimate local multipliers. The identifying assumption is that federal government value added does not systematically react within one quarter to economic conditions of states that receive a disproportionate amount of national spending, a weaker assumption than our baseline approach.

The scaled federal shocks should also accommodate the possible concern that balanced budget requirements at the state level influence the results. States with stricter budget requirements, for example, might in general react differently to fiscal conditions than other states (Poterba, 1994; Bohn \& Inman, 1996), while Cashin et al. (2017) find a sharp reduction in state and local government purchases in the postcrisis recovery due to balanced budget rules. A strict budget requirement may also make government spending of an individual state sensitive to changes in state output within one quarter, which would be at odds with our baseline Blanchard and Perotti (2002) identifying assumption. ${ }^{9}$

\footnotetext{
${ }^{9}$ The key question is whether this response is within one quarter. For example, Costello, Petacchi, and Weber (2017) document that taxes and spending of states with strict balanced budget requirements do not react differently within the first year relative to states with weak budget requirements. This is only the case in the subsequent year. In general, it is hard to find
} 
Figure 3.-Sensitivity of Benchmark Multipliers

(a) scaled federal spending
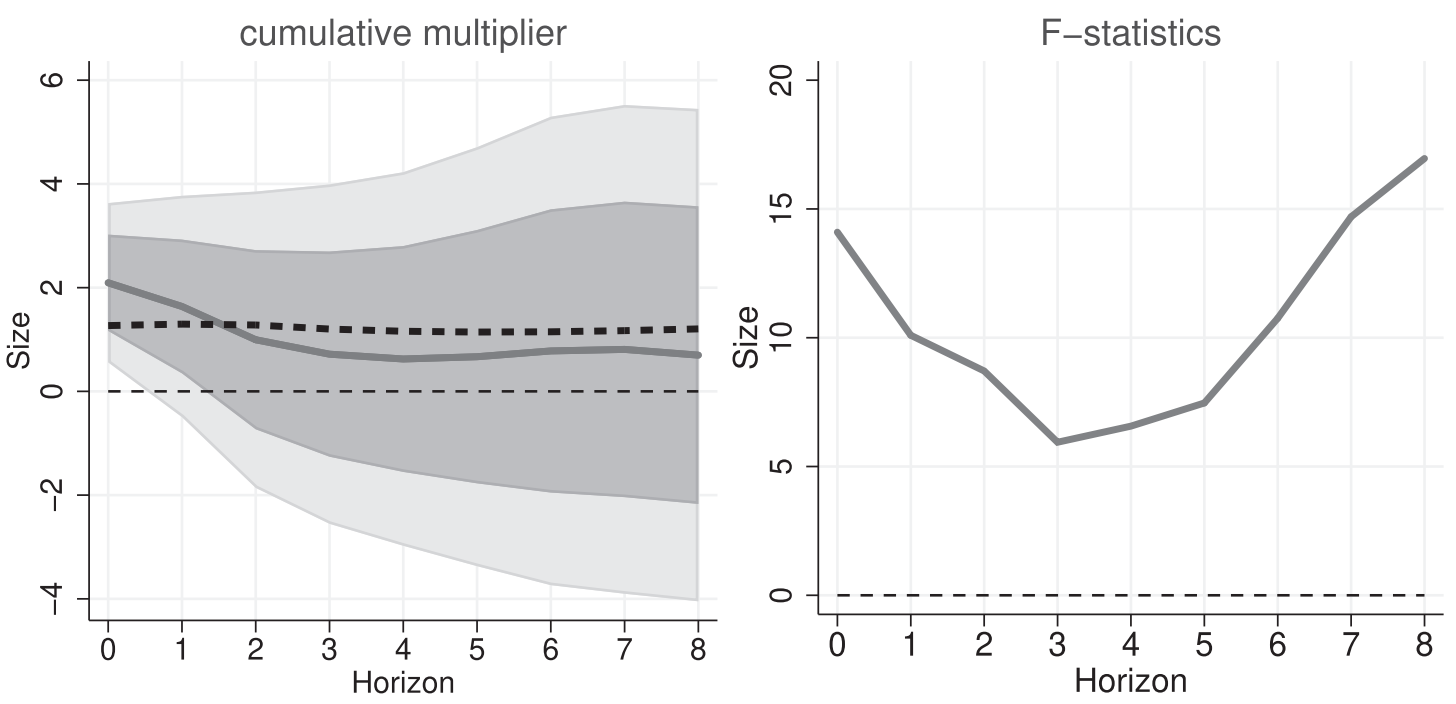

(b) mean group estimator

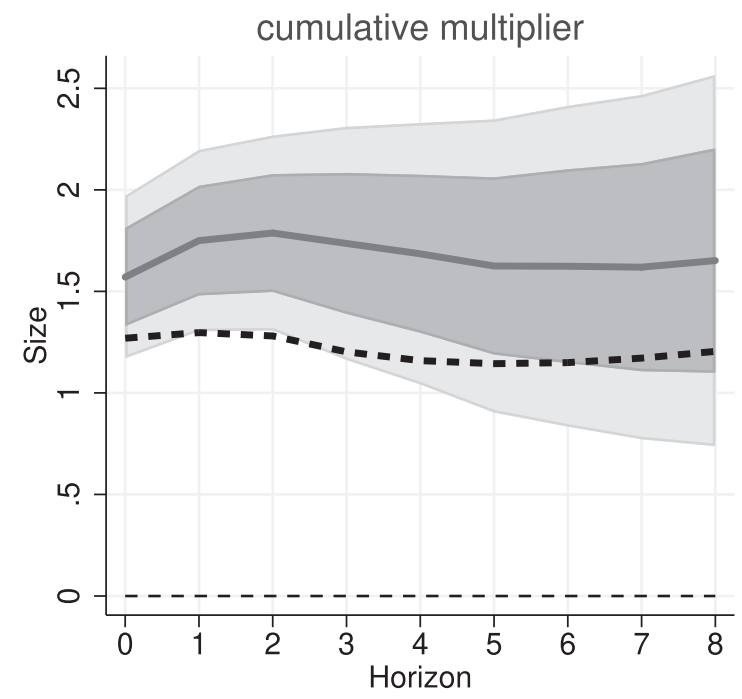

Bands are $68 \%$ (dark) and 90\% (light) confidence intervals. The dashed black lines are the point estimates of the benchmark results.

Figure 3 shows the average cumulative relative multipliers that are estimated using the alternative scaled national government spending shocks. The graphs also include the point estimates of the benchmark results for comparison. The impact multiplier is around 2 and larger than the benchmark multiplier, but decreases below 1 at longer horizons. A caveat of

(anecdotal) evidence that states do react within the quarter to a projected deficit or changes in revenues. Notice also that there is considerable variation in the implementation of balanced budget requirements, which typically apply to the general fund budget but exclude, for example, state-funded special revenue funds and federal funds. Furthermore, state governments are quite creative to temporarily alleviate the requirements, for example, by using asset sales or interfund transfers of money. In fact, when we split the sample between states that have strict and weak balanced budget requirements, we find similar relative multipliers (results available on request). Hence, it is not likely that different budget requirements have an impact on our benchmark results. these results, however, is that the point estimates are quite imprecise. The lower $F$-statistics also point to a lower strength of the instrument and potential weak instrument bias. Due to this imprecision and the fact that the results are not very different from our benchmark approach, we will proceed only with the latter in the balance of the paper.

As another robustness check, figure 3 shows cumulative relative multipliers that are estimated with a mean group approach, which allows for cross-state heterogeneity in the slope coefficients. Given that we find considerable heterogeneous multipliers in section III, the assumption of homogeneous slopes of the fixed-effects estimator may distort the results. In order to estimate relative cumulative multipliers and control for common shocks, we orthogonalize the series to state-specific and time-specific effects before performing the state-by-state estimations. As can be observed in the figure, 
the point estimates of the cumulative multiplier are somewhat larger and qualitatively similar to the benchmark results; the multiplier ranges between 1.6 and 1.8 depending on the horizon. Notice, however, that the mean group estimator requires a relatively long time dimension, which is a limitation of the state-level data set. This is even more the case for the large number of coefficients that we need to estimate in section III. In addition, individual state-level regressions lack sufficient variation in the data to properly identify these (interaction) coefficients, which heavily rely on the cross-section dimension of the data set (e.g., household debt). In the remainder of the paper, we therefore use only the fixed-effects estimator. Overall, we conclude that our benchmark results offer robust estimates of average state-level cumulative multipliers.

\section{E. Fiscal Policy Spillovers across States}

Since we are estimating the impact of government spending on the relative output of states, the above results could under- or overestimate the local (and total) effects of government spending on economic activity if there are positive or negative spillovers across states. For example, an increase in output in one state associated with lower activity elsewhere could also induce a large shift in relative output (Cochrane, 2012). This could, for example, be the case if a rise in output in one state induces workers to immigrate from other states. An implicit premise of estimating relative multipliers is also that the individual state receives spending, but other states essentially have to partly pay for it. These features can entail negative spillovers effects, in which case the estimated multipliers are an overestimation of the total effects of spending on a state. On the other hand, there could be positive spillovers to other states through trade, which leads to an underestimation of the impact on local and aggregate economic activity. Dupor and Guerrero (2017) indeed find small, positive spillovers between states and their major trading partner, while Serrato and Wingender (2016) do not find sizable spillover effects across neighboring U.S. counties. Conversely, Auerbach and Gorodnichenko (2013) find fiscal spillovers through trade among OECD countries that are statistically and economically significant.

In this section, we assess whether trade linkages affect the relative multipliers that we have estimated and whether trade partners benefit from government spending. In the spirit of Auerbach and Gorodnichenko (2013), we first construct for each state a trade-weighted sum of government value added and government spending shocks in partner states. For details of the construction, we refer to the data appendix. We then extend equation (1) with the trade-weighted sum of government value added. ${ }^{10}$ Figure 4 a shows the estimated cumulative multipliers and cumulative trade-weighted spillover ef-

\footnotetext{
${ }^{10}$ We now have two shocks (own state and other state's spending shocks) that are used as instruments for cumulative government spending by state $i$ and its trade partners. Notice also that we do not report $F$-statistics for possible weak instruments because this test applies only for IV regressions with one endogenous regressor.
}

fects. A first important observation is that the cumulative multipliers of own-spending shocks are similar to the benchmark average multipliers. Our results are thus robust for this extension. ${ }^{11}$ Furthermore, figure 4 a reveals a positive spillover effect from spending shocks in trade partners. The contemporaneous spillover impact is even 0.6. However, the positive spillover effects vanish after one quarter. Notice that the uncertainty of the estimates is also quite high.

As an alternative, similar to Dupor and Guerrero (2017), figure $4 \mathrm{~b}$ shows the own multiplier and spillover effects from a spending shock in the main trading partner. For 47 states (including the District of Columbia), the major trade partner shares borders. Again, we find moderate positive spillovers, which confirms a favorable trade channel. Does this imply that non-trade partners have to bear the costs? This does not seem to be the case. Specifically, figure $4 \mathrm{c}$ also shows the impact of a government spending shock in the least important trade partner, which turns out to be insignificant. Overall, these results suggest that there are likely positive spillover effects across states through trade, albeit quite moderate, while other states do not have to carry the burden of local spending shocks. The average multipliers that we have documented in section IIC are hence a lower bound of the local effects of government spending.

\section{Heterogeneous Relative Multipliers}

Fiscal multipliers that are estimated in empirical studies measure the effectiveness of an average government spending shock within the sample period. However, the actual size of the multiplier in a specific state at a particular time may significantly differ from the general tendency. Specifically, multipliers are not structural characteristics of the macroeconomy, and their size can differ over time and across states. From a policy perspective, in the presence of multipliers that change depending on underlying conditions of the economy, linear estimates like the ones shown in section IIC may provide a misguided source of information. In this section, we assess the relevance of some key possible determinants of relative fiscal multipliers across states.

\section{A. Determinants of Relative Multipliers}

Blanchard and Leigh (2013) have argued that the failure to recognize an upward change in the magnitude of fiscal multipliers during the Great Recession and its aftermath has significantly contributed to the growth forecast errors that policy institutions make. Accordingly, the literature has shown increasing interest in the analysis of how the effectiveness of fiscal policy may change under certain economic and financial conditions. The amount of private debt accumulation prior to

\footnotetext{
${ }^{11}$ This is not the case for the spillover effects. Specifically, when owngovernment spending is not included in this estimation, we find a much higher spillover multiplier of approximately 1.5 on impact, which can be explained by a positive correlation between own-spending shocks and those of trade partners.
} 
Figure 4.-Fiscal Policy SPILlovers

(a) trade-weighted partners
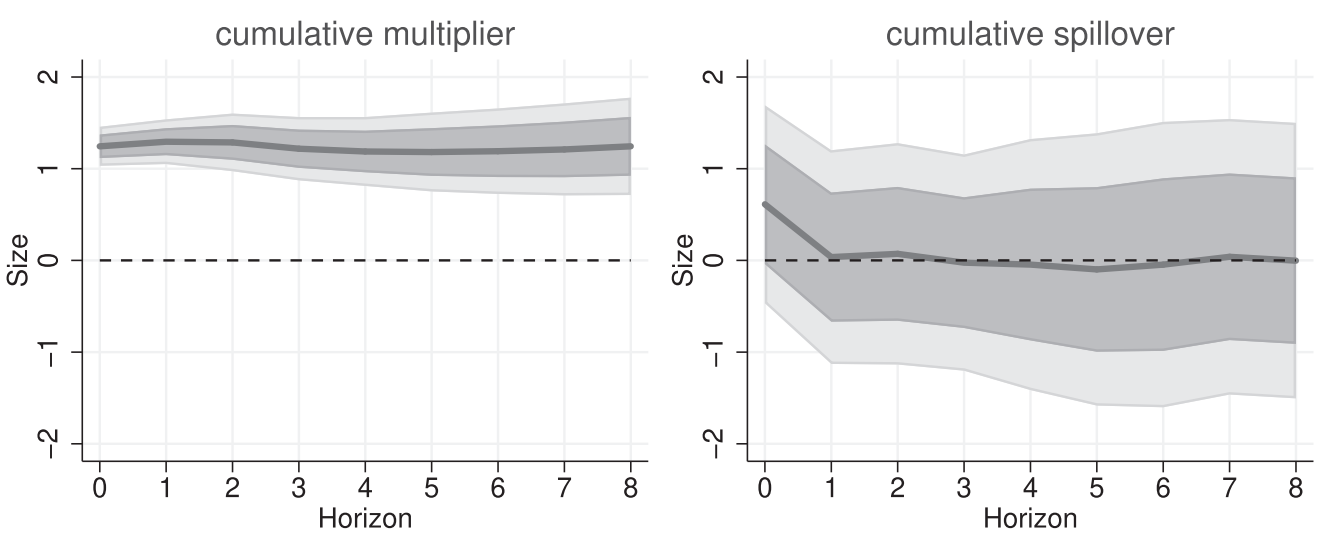

(b) top trade partner
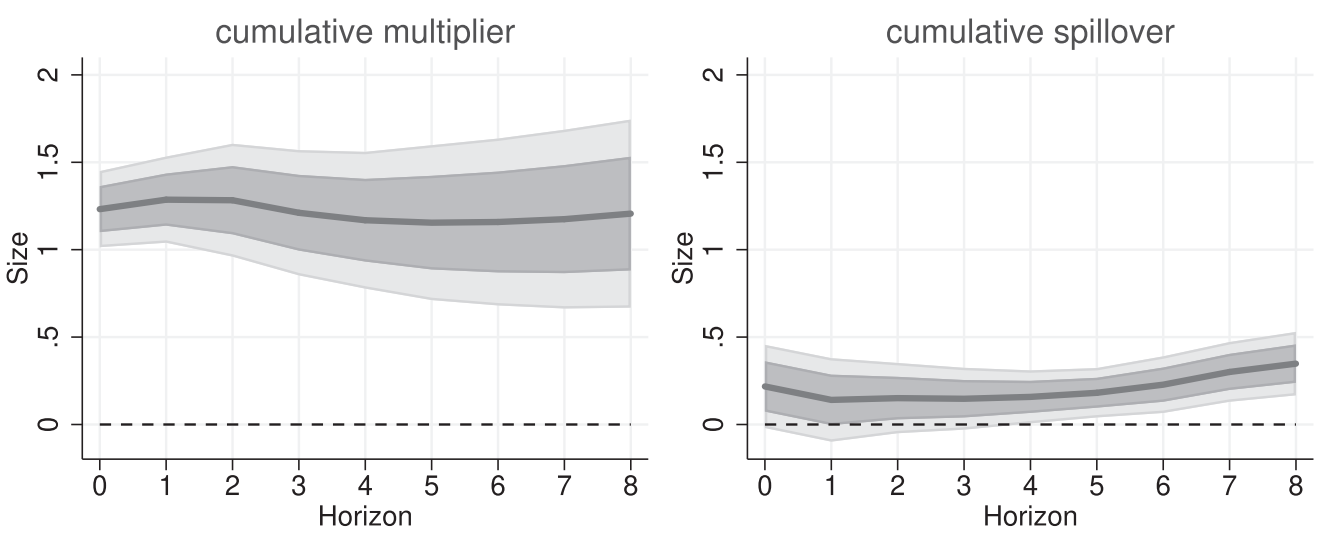

(c) least important trade partner
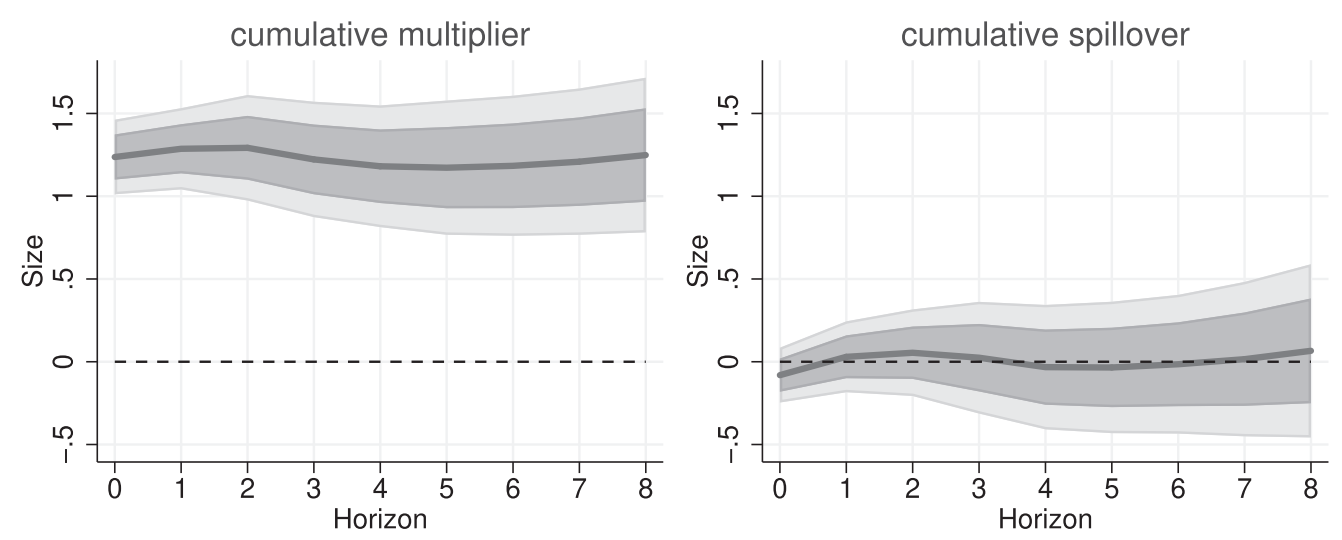

Bands are 68\% (dark) and 90\% (light) confidence intervals.

the start of the Great Recession and the impact of leverage on the recession have directed researchers toward exploring the role played by the business cycle and the degree of private indebtedness in affecting the transmission of fiscal policy. We examine whether both conditions, as well as their interaction, matter for relative multipliers across states. ${ }^{12}$

\footnotetext{
${ }^{12}$ Other popular determinants of multipliers that have been documented in the literature are the stance of monetary policy (Christiano, Eichenbaum,
}

Business cycle. The influence of the business cycle on fiscal multipliers reflects the Keynesian argument that government spending is more effective during periods of economic slack. From a theoretical perspective, Michaillat (2014) obtains countercyclical multipliers based on a model where the

\& Rebelo, 2011) or the level of government debt (Perotti, 1999). However, both features cannot explain the magnitude of relative multipliers. One of the advantages of disaggregate data is hence that these features cannot distort the estimations of the role of the other determinants. 
Figure 5.-Cross-State Variation of ECONOMic Conditions over Time
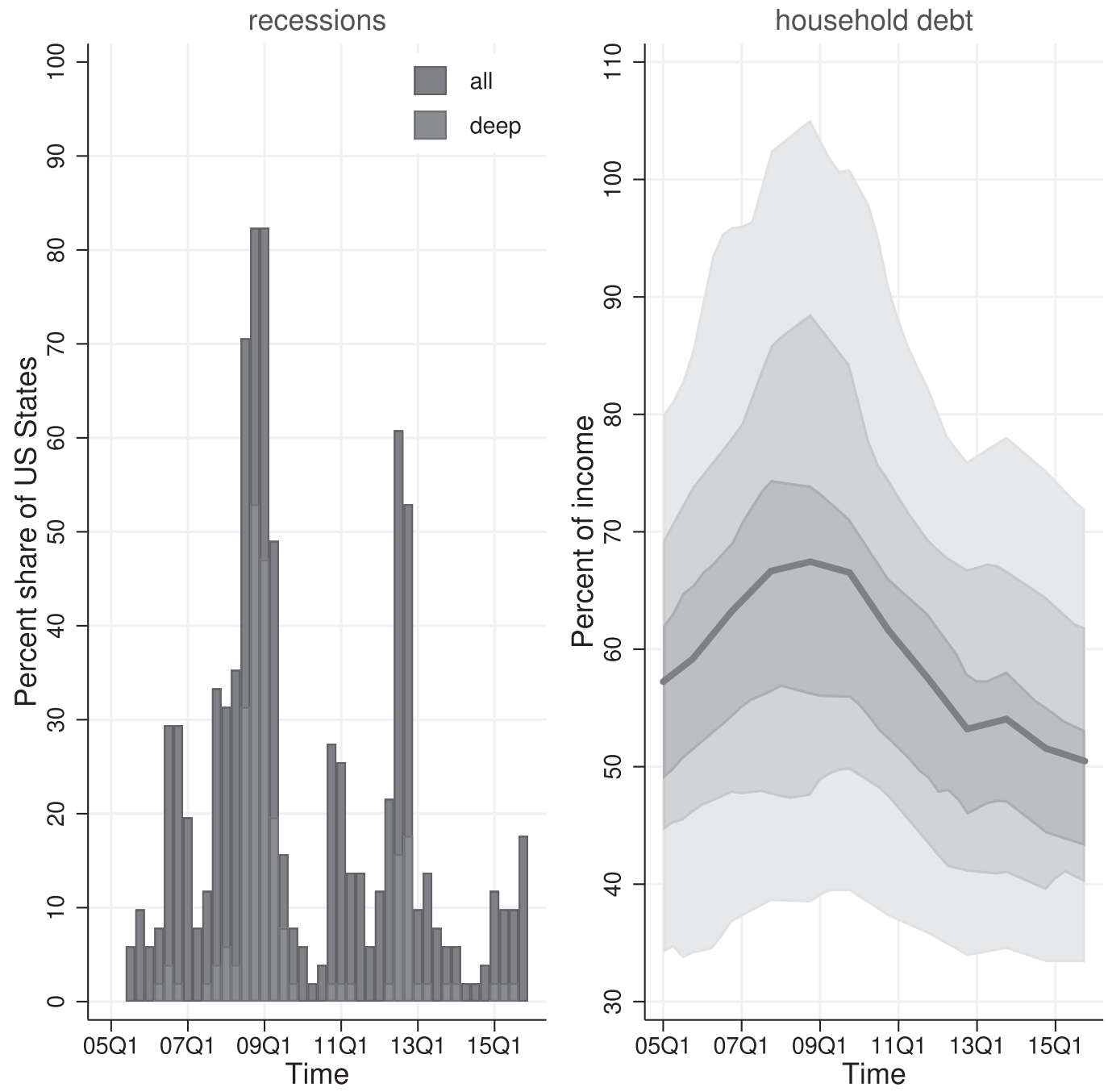

The bar graph depicts the percentage of U.S. states in recession (deep recession) in each quarter of our sample. The total number of recessions (deep recessions) in our sample is 406 (118), for a total of 1,581 observations. The green line shows the cross-state average of household debt over time. The bands show different percentile intervals: 35th-65th (30\%), 20th-80th (60\%), and 5th-95th (90\%).

presence of search-and-matching features in the labor market leads to less crowding out of private sector resources in recessions. Canzoneri et al. (2016) retrieve stronger multipliers in recessions as a result of countercyclical financial frictions and credit constraints in a macromodel with costly financial intermediation, which results in a stronger financial accelerator in recessions. The strength of the financial accelerator and the magnitude of the multiplier depend on the spread between borrowing and lending at the moment of the fiscal impulse, that is, the intensity of financial frictions. Hence, this mechanism might have been particularly important in the financial crisis.

Several empirical studies have focused on the effects of fiscal policy during recessions or periods of slack. For example, Auerbach and Gorodnichenko (2012a, 2012b) find that aggregate U.S. multipliers are larger during recessions than in expansions. According to Caggiano et al. (2015), this is even more the case in deep recessions. Fazzari, Morley, and Panovska (2015) find larger and more persistent government spending multipliers in periods of low-capacity utilization, while Jordà and Taylor (2015) show that fiscal consolidations translate in stronger output declines when implemented in a slump. ${ }^{13}$ At the regional level, Nakamura and Steinsson (2014), Brückner and Tuladhar (2014), and Serrato and Wingender (2016) all document a larger multiplier during periods of economic slack.

The left panel of figure 5 shows the incidence of state-level recessions in our sample. It shows the percentage of U.S. states experiencing a recession at each quarter of the sample period, where recessions are defined as a negative state-level, real quarter-on-quarter GDP growth for at least two consecutive quarters. For example, $80 \%$ of the states were experiencing a downturn during the Great Recession between 2008Q1 and 2009Q2, while the remaining 20\% were not. Also outside

\footnotetext{
${ }^{13}$ Using more than a century of U.S. data, Ramey and Zubairy (2018) find that this is the case only for government spending shocks that are identified with the Blanchard-Perotti approach, not for military spending news shocks.
} 
this period, several states experienced a prolonged decline in real GDP. For example, in the second half of 2012, nearly $60 \%$ of the states suffered a drop in activity of at least two consecutive quarters. Overall, the frequency of recessions has been $26 \%$ in the sample period. This could result in heterogeneous multipliers.

In the empirical analysis, we make a distinction between recessions and deep recessions, where the latter are defined as periods in which the drop of real GDP was greater than the sample average decline for at least two quarters. The deep recessions are also shown in the left panel of figure 5 (red bars) and account for approximately one-third of all recessions (7\% of all sample observations). This simple split-up allows us to examine the influence of the intensity of a recession on state government spending multipliers. This can be motivated by the findings of Caggiano et al. (2015) at the aggregate level. In addition, the intensity of financial frictions and the financial accelerator mechanism described in Canzoneri et al. (2016) is likely much stronger in severe recessions. Besides state-level binary dummy variables for recessions and deep recessions, we also report results for a continuous recession indicator as proposed in Auerbach and Gorodnichenko (2012b). In particular, we employ a transition function based on smoothed GDP growth that assigns probability weights between 0 and 1 for being in a recession. ${ }^{14}$

Household debt. Theoretical studies have more recently advanced the idea that private indebtedness may also be important for the size of government spending multipliers. Specifically, debtors tend to have a larger marginal propensity to consume (MPC) out of current income relative to lenders (Kaplan, Violante, \& Weidner, 2014; Misra \& Surico, 2014; Cloyne \& Surico, 2017; Baker, 2018), which implies that they increase (decrease) their consumption much more to changes in income than others. Higher MPCs, in turn, could result in higher multipliers. Such a mechanism has been formally demonstrated by Eggertsson and Krugman (2012) and Andrés et al. (2015) by assuming that debtors face binding borrowing constraints. In Kaplan et al. (2014) and Kaplan and Violante (2014), instead, debtors who own large illiquid assets (e.g., houses) may display so-called hand-to-mouth behavior independent of the presence of borrowing constraints. A common implication of these models is that fiscal policy during the previous decade might have been much more effective in states with high debt burdens. ${ }^{15}$

A number of empirical studies indeed find a positive impact of household debt on the size of fiscal multipliers. Bernardini and Peersman (2018) find the aggregate U.S. spending multiplier over the past century to be higher in periods of private debt overhang relative to periods when debt is be-

\footnotetext{
${ }^{14} I\left(z_{i t}\right)=\frac{\exp \left(\gamma z_{i i}\right)}{1+\exp \left(\gamma z_{i t}\right)}$ with $z_{i t}=4$-quarter backward moving average of negative real GDP growth. We set $\gamma=2.5$, which closely mimics the frequency of state-level recessions in our sample that are defined as two subsequent quarters of negative growth.

${ }^{15}$ Some recent studies find that high debt could also be associated with low MPCs (e.g., Sahm, Shapiro, \& Slemrod, 2015; Japelli \& Pistaferri, 2014).
}

low its trend. Klein (2017) confirms this finding for a panel of OECD countries and the consequences of austerity measures. Finally, Demyanyk et al. (2017) use cross-sectional data of U.S. metropolitan areas and find that output is relatively more affected by government spending in areas with more consumer debt.

The amount of household debt may also result in heterogeneous multipliers across states. Private indebtedness has indeed been very different across states. This is illustrated in the right panel of figure 5, which summarizes the variation of household debt across states in our sample period. The information is based on the second recently released data source that we use in this paper, the Consumer Credit Panel of the FRBNY. The data are annual. Household indebtedness is measured as the outstanding value of household mortgage debt in a U.S. state divided by personal income. ${ }^{16}$ The crosssectional average captures the hump-shape dynamics in the debt-to-income ratio, which went from $60 \%$ in 2005 to nearly $68 \%$ at the peak and subsequently dropped to $50 \%$ at the end of the sample. Besides important time variation in the average, the figure documents considerable cross-sectional variation. At the peak of the debt cycle, there are states with debt ratios close to $40 \%$, as well as states with household debt levels greater than $100 \%$. The sizable variation in the household debt-to-income ratio enables us to analyze the existence of an association between the size of state multipliers and the degree of household indebtedness in the economy.

Interaction of household indebtedness and the business cycle. The bulk of the empirical literature on time-varying multipliers focuses on a single economic condition as a possible driver. However, it can be argued that the influence of household debt and the stance of the business cycle on multipliers are intertwined, in particular for the decade under analysis. Specifically, households' borrowing constraints are typically more relevant during recessionary periods due to varying attitudes toward leverage and financial accelerator effects depending on the level of economic activity (Bernanke \& Gertler, 1989; Peersman \& Smets, 2005). Furthermore, Eggertsson and Krugman (2012) show that the amount of private debt augments the multiplier at times when households are forced into rapid deleveraging. Such deleveraging was exactly what was happening and a key source of the (deep) recessions in many states in the sample period (Mian \& Sufi, 2010). For example, Demyanyk et al. (2017) find larger multipliers in metropolitan areas with higher consumer debt in the (deleveraging) period 2007 to 2009, but not for the period 2003 to 2005. Kaplan and Violante (2014) find that a severe recession leads to a reduction of hand-to-mouth behavior by wealthy households, which in turn leads to a smaller aggregate consumption reaction following a fiscal spending shock.

\footnotetext{
${ }^{16}$ Mortgage debt provides a better link to economic theory than total household debt (which also includes credit card debt, auto loans, and student debt). Notice, however, that mortgage debt accounts by far for the largest share of total household debt. In addition, our results are robust to the use of total household debt.
} 
By focusing on both level of household debt and the stance of the business cycle, and their interaction, we can assess the possible mutual influence of these factors on the size of the multiplier.

\section{B. Empirical Specification}

To investigate the joint role played by recessions and household debt in affecting the size of state government spending multipliers, we allow the model in equation (1) to linearly depend on the state of the business cycle $c_{i t-1}$ and the level of household debt $d_{i t-1}$, and their interaction. ${ }^{17}$ The model becomes

$$
\begin{aligned}
\sum_{l=0}^{h} \tilde{y}_{i t+l}= & \beta_{h}\left(\sum_{l=0}^{h} \tilde{g}_{i t+l}\right)+\beta_{h}^{c}\left(c_{i t-1} \sum_{l=0}^{h} \tilde{g}_{i t+l}\right) \\
& +\beta_{h}^{d}\left(d_{i t-1} \sum_{l=0}^{h} \tilde{g}_{i t+l}\right)+\beta_{h}^{i n t}\left(c_{i t-1} d_{i t-1} \sum_{l=0}^{h} \tilde{g}_{i t+l}\right) \\
& +\gamma_{h}(L) c \tilde{t} r_{i t}+\gamma_{h}^{c}(L) c_{i t-1} c \tilde{t} r_{i t}+\gamma_{h}^{d}(L) d_{i t-1} c \tilde{t} r_{i t} \\
& +\gamma_{h}^{i n t}(L) c_{i t-1} d_{i t-1} c \tilde{t} r_{i t}+\alpha_{i h}+\delta_{t h}+\varepsilon_{i t+h}, \quad(5)
\end{aligned}
$$

where $\sum_{l=0}^{h} \tilde{g}_{i t+l}, c_{i t-1} \sum_{l=0}^{h} \tilde{g}_{i t+l}, d_{i t-1} \sum_{l=0}^{h} \tilde{g}_{i t+l}, c_{i t-1} d_{i t-1}$ $\sum_{l=0}^{h} \tilde{g}_{i t+l}$ are instrumented by shock it $_{i t-1}$ shock $_{i t}$, $d_{i t-1}$ shock $_{i t}$, and $c_{i t-1} d_{i t-1}$ shock $_{i t}{ }^{18}$ As Ozer Balli and Sørensen (2013) suggested, the right-hand-side variables are all centered around relative means in the estimations, that is, the grand mean adjusted for each state $i$ and at each point in time $t$ by the respective state and time group means, which is mathematically equivalent to employing a fixed-effects estimator. The demeaning of the regressors allows the exploration of the same variation used for the estimation of the baseline multiplier while making the estimation robust to the presence of state and/or time-varying slopes. ${ }^{19}$ In equation (5), $\beta_{h}$ measures the average multiplier, that is, the multiplier

\footnotetext{
${ }^{17}$ The use of one-period lagged economic state variables guarantees that they are not endogenously affected by the shock. We also add the variables $c_{i t-1}, d_{i t-1}$ and their interaction as regressors, which is standard in multiple regression models with interaction terms.

${ }^{18}$ As discussed in section II, our identification approach assumes that government spending does not react instantaneously to macroeconomic shocks. This also applies to the state-dependent multipliers reported in this section. A potential caveat raised by a referee is that large and persistent shortfalls in states' revenues, which is typically the case in (deep) recessions, could force states to take extraordinary measures, such as cutting back spending to balance their budgets. Notice, however, that this could distort the results of the estimations only if the reduction in spending occurs within the same quarter of the decline in economic activity, which is not likely the case. Due to weak instrument problems (extreme low $F$-statistics for several horizons) and error bands that explode, it is not possible to assess the robustness of the results in this section using scaled federal government spending shocks.

${ }^{19}$ Notice that for the estimation of the average (linear) multiplier in section II, a centering of the variables around relative means produces exactly the same results as those reported. Formally, a generic panel data regression $y_{i t}=\alpha_{i}+\delta_{t}+\beta x_{i t}+u_{i t}$ is equivalent to $y_{i t}=\alpha_{i}^{\prime}+\delta_{t}^{\prime}+$ $\beta\left(x_{i t}-x_{i .}-x_{. t}+x_{. .}\right)+u_{i t}$ or $\left(y_{i t}-y_{i .}-y_{. t}+y_{. .}\right)=\beta\left(x_{i t}-x_{i .}-x_{. t}+\right.$ $\left.x_{. .}\right)+u_{i t}$.
}

for a situation when both economic state indicators are at their mean. $\beta_{h}^{c}$ and $\beta_{h}^{d}$ are the additional effects associated with, respectively, a recession and a 1-standard deviation change in household debt, assuming that the other indicator is at its mean, while $\beta_{h}^{\text {int }}$ measures the additional effects associated with a 1-standard deviation change in household debt while being in a recession. ${ }^{20}$ In the figures that follow, we report linear combinations of these coefficients to summarize the results.

\section{Results}

Figure 6 shows the influence of (deep) recessions and household indebtedness on cumulative government spending multipliers. In each graph, the blue line represents the point estimate, whereas the bands show the $68 \%$ and the $90 \%$ confidence intervals based on Driscoll-Kraay standard errors. ${ }^{21}$ To be comparable to existing studies and to offer useful benchmarks for policymakers, we convert the estimated parameters of equation (5) to specific situations. ${ }^{22}$ More specifically, we show the average multiplier in, respectively, a (deep) recession and expansions (outside deep recession) for a situation where household debt is at its sample mean. For both phases of the business cycle, we also show the additional impact on the cumulative multiplier of a 1-standard deviation increase of household debt from the sample mean. The right-hand part of the figure depicts the estimated differences with confidence bands.

The results reveal considerable heterogeneity of government spending multipliers within the sample period. In expansions, multipliers have been around 1 on impact in order to gradually decline at longer horizons. The magnitudes and dynamics of multipliers in (deep) recessions are, however, very different. Specifically, we obtain multipliers that are between 1.5 and 2 in recessions. In contrast to expansionary periods, multipliers remain at this level over the entire two-year horizon. A possible explanation of more persistent output effects of fiscal policy shocks initiated during recessions may be hysteresis effects (Delong \& Summers, 2012). As can be observed in figure 7 , which shows the underlying impulse responses of government value added and GDP in expansions and (deep) recessions, the dynamics of government spending is quite similar in both phases of the cycle, while there is indeed a temporary rise of real GDP in expansions and a persistent rise in recessions. Furthermore, we find substantially higher multipliers in deep recessions, a finding that is in line with the aggregate results of Caggiano et al. (2015). In

\footnotetext{
${ }^{20}$ For a convenient interpretation of the role of household debt, we normalize this variable by its standard deviation over the sample period.

${ }^{21}$ Notice again that we do not report $F$-statistics for possible weak instruments because the critical values of Montiel Olea and Pflueger (2013) apply only to IV regressions with one endogenous regressor. The statistics themselves are, however, almost always above 40.

${ }^{22}$ For example, the multiplier in normal times for a situation where household debt is at its sample mean is $\beta_{h}-f r \beta_{h}^{c}$, where $f r$ is the grand mean of the variable $c$ (i.e., frequency of recessions in the sample). Similarly, the multiplier in a recession is equal to $\beta_{h}+(1-f r) \beta_{h}^{c}$.
} 
Figure 6.-EFFects of Recessions and Household Debt on Relative Multipliers

(a) recessions

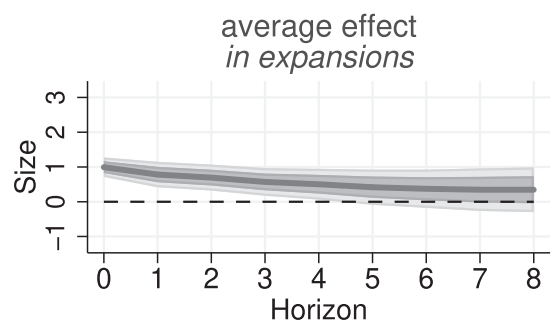

additional effect of debt in expansions
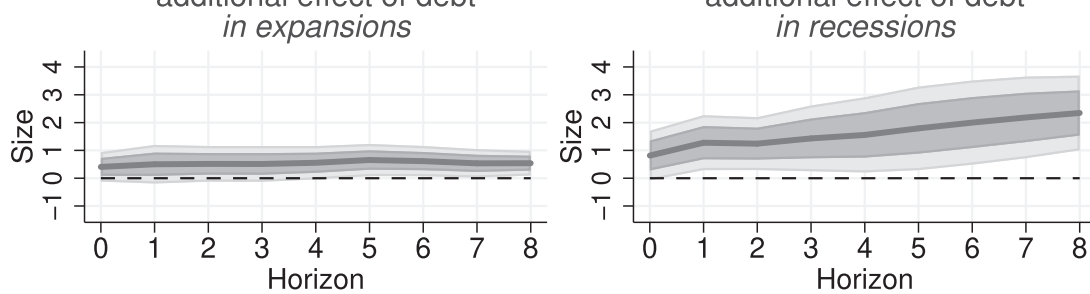

average effect

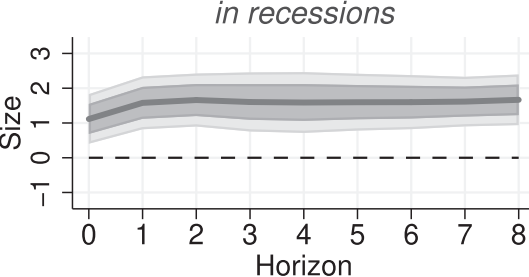

additional effect of debt in recessions

(b) deep recessions
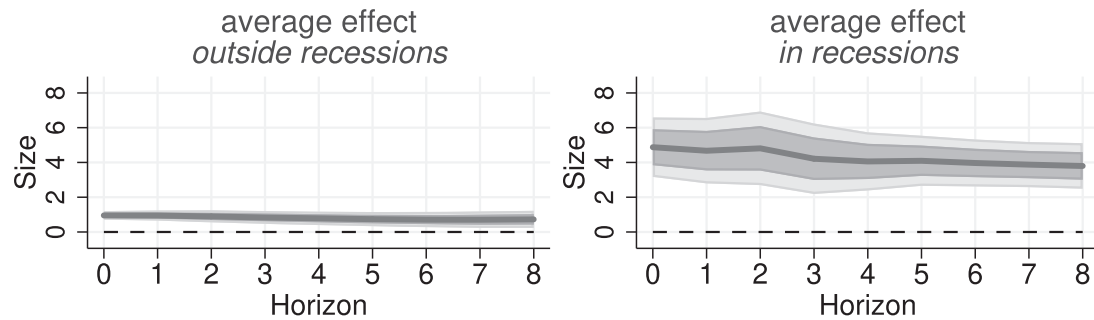

additional effect of debt outside recessions
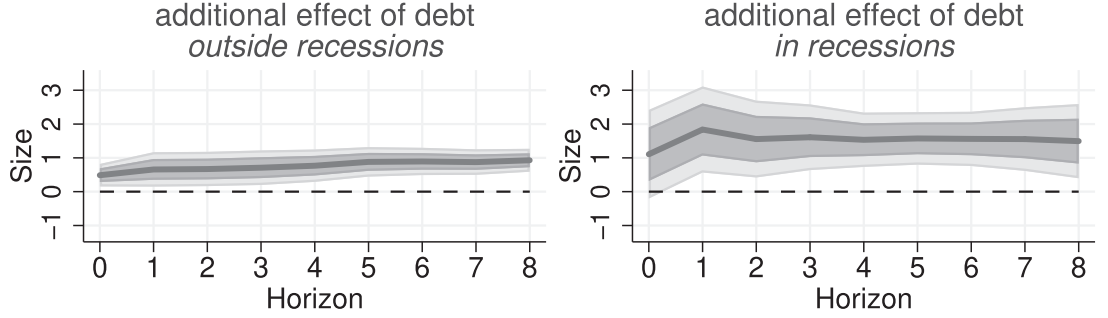

(c) continuous recession indicator

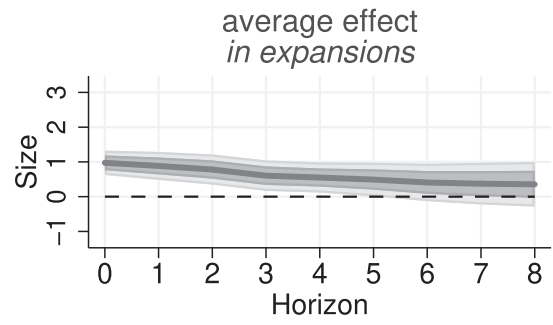

additional effect of debt in expansions

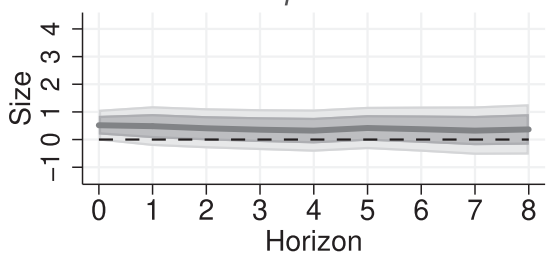

average effect in recessions

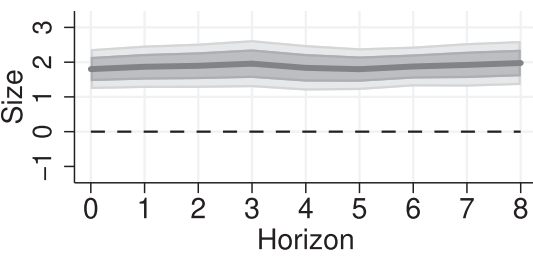

additional effect of debt in recessions

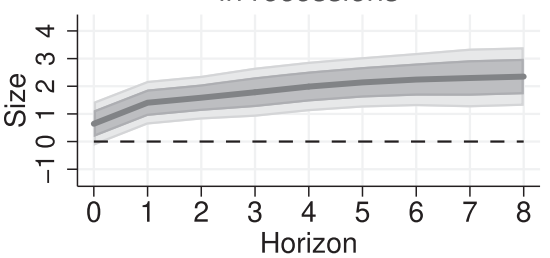

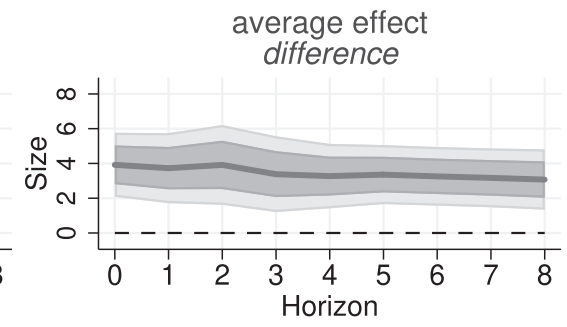

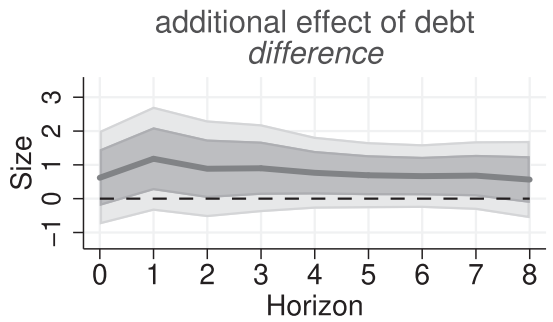

average effect difference

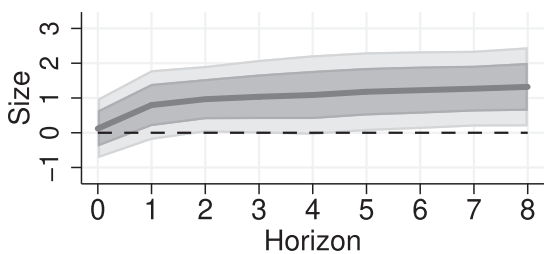

additional effect of debt difference

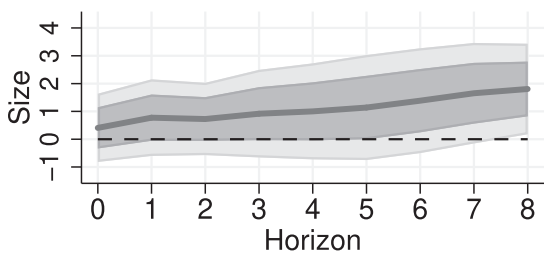

Horizon

erage effect difference

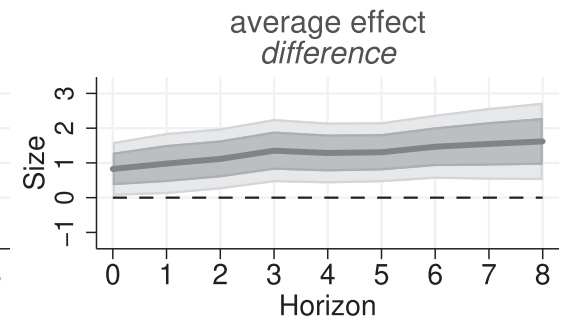

additional effect of debt difference

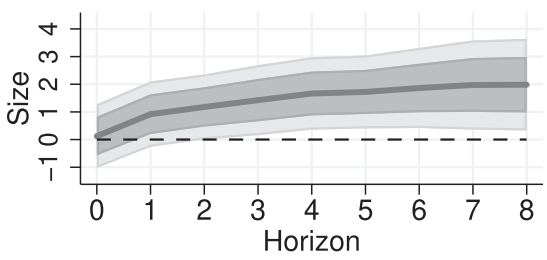

Bands are $68 \%$ (dark) and $90 \%$ (light) confidence intervals. The additional effect of debt is normalized to 1-standard deviation. 
Figure 7.-Underlying StATE-DEPENDENT IMPUlse RESPONSES

(a) recessions

\section{government value added}
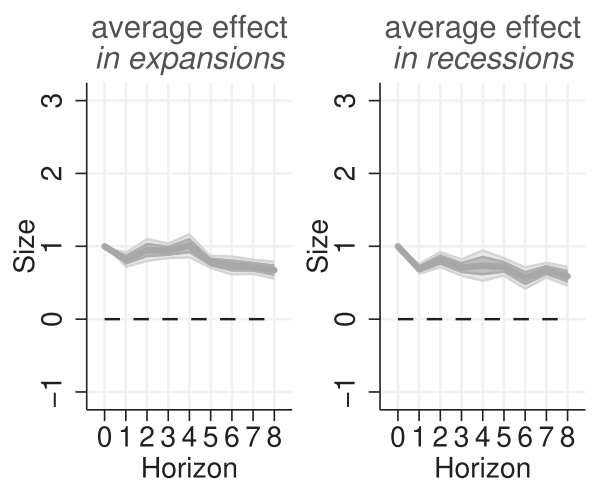

gross domestic product
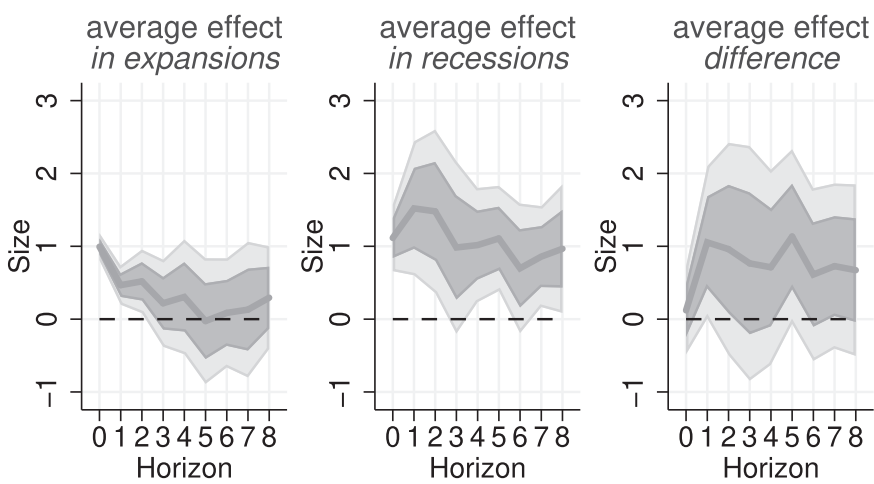

(b) deep recessions

government value added
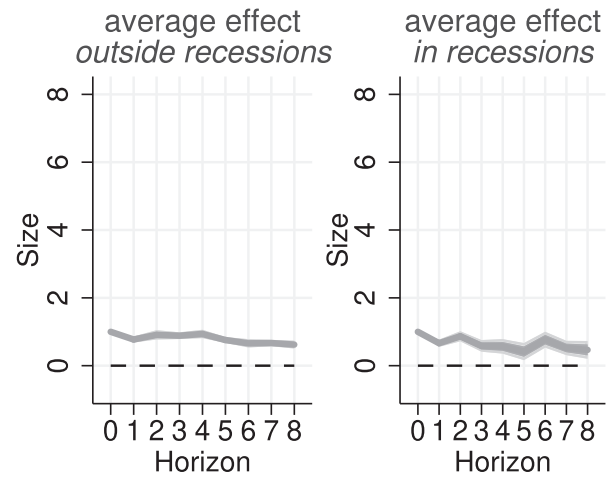

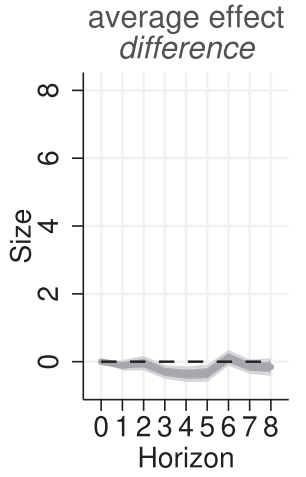

(c) continuous recession indicator

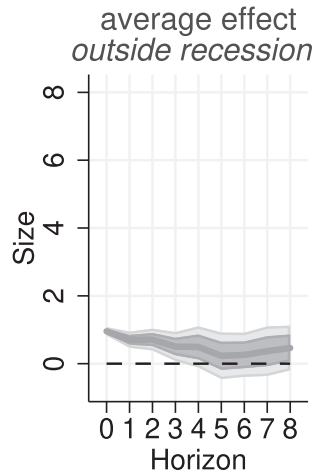

gross domestic product
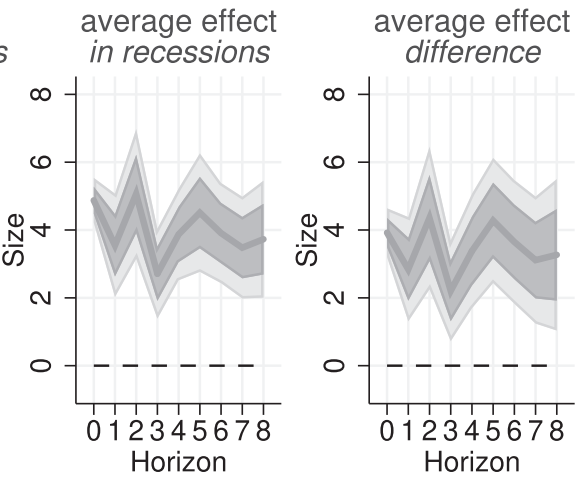

government value added
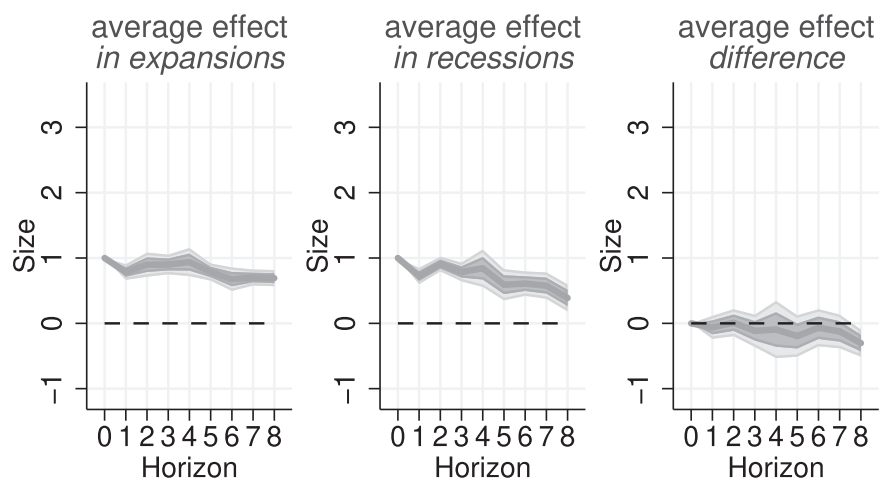

Bands are 68\% (dark) and 90\% (light) confidence intervals.

particular, state relative government spending multipliers in severe recessions turn out to be above 4 on impact and again remain at such a high level at longer horizons. The business cycle is hence an important determinant of relative multipliers.

The degree of household indebtness is also crucial for the size of state multipliers. More precisely, we find a nonnegligi- gross domestic product
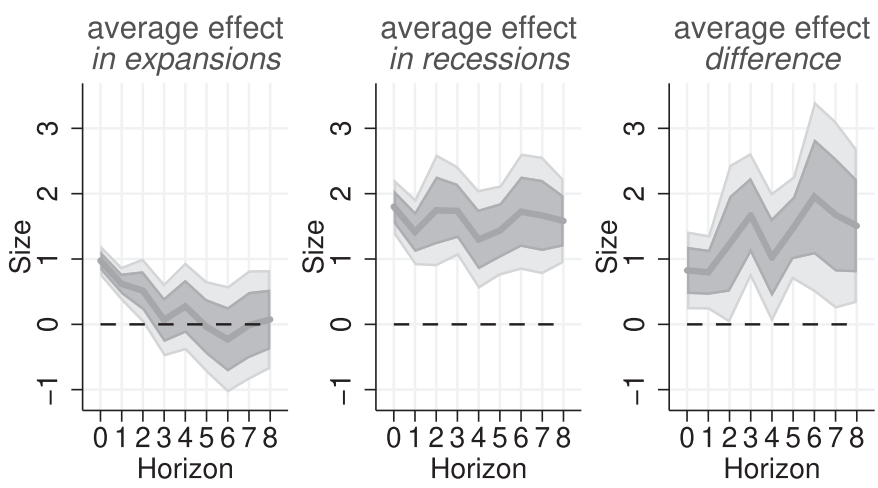

ble positive effect of household debt on the multiplier outside (deep) recessions, which is statistically significant. When the household debt-to-income ratio in an individual state relative to the sample mean is 1 standard deviation higher, the multiplier turns out to be roughly 0.5 larger. Hence, in contrast to Demyanyk et al. (2017), we also find an important role of household debt in a boom. Interestingly, household 
indebtness becomes a significantly more important driver of multipliers in recessions. In particular, when household debt is 1 standard deviation higher, the state's multipliers increase by approximately 2 in (deep) recessions. ${ }^{23}$ In other words, the results suggest that in recessionary periods, not only the average size of the multiplier tends to increase, but also its dependence on the degree of household indebtedness. This finding is consistent with, for example, tighter borrowing constraints and more financial frictions in recessions, as discussed in Eggertsson and Krugman (2012) and Canzoneri et al. (2016).

Overall, these results imply that average (linear) relative government spending multipliers are not very useful for policymakers and forecasters in real time. The stance of the business cyle, the amount of private debt, and the interaction of both conditions should be taken into account to assess and predict the consequences of fiscal policies on individual states.

\section{Aggregate Effects of Spending Redistributions}

Local multipliers are key indicators to understand if and to what extent fiscal policy is effective at stabilizing regional business cycles or smoothing asymmetric shocks. Differently from aggregate multipliers, however, they are not necessarily informative about the ability of fiscal policy to affect the economy as a whole. To understand why, notice that relative multipliers measure the impact of a shift in relative government spending on the relative economic activity of a state, holding national effects constant. A rise of output in one state and a corresponding decline of output in another state could have a strong impact on relative GDP, while aggregate GDP remains constant. As a result, economic studies focusing on aggregate economic stabilization typically do not attach much importance to local multipliers.

In section IIE, we showed that spillover effects of government spending shocks on other states are moderately positive. Increases in local spending thus likely also stimulate aggregate economic activity. However, as Ramey (2011b) argued, if there are large, heterogeneous effects of fiscal policy across states, targeted redistributions of government spending across states might be able to generate sizable aggregate effects on economic activity. More precisely, the results of this paper suggest that keeping aggregate government spending constant, a mere redistribution of spending toward states in a (deep) recession or characterized by a high debt burden in the household sector should be able to stimulate aggregate GDP. In this section, we test this conjecture more directly. To do this, we first construct a simple indicator that reflects redistribution of government spending from states with potential low multipliers to states that have likely large multipliers inspired by the results of section III,

\footnotetext{
${ }^{23}$ Somewhat surprisingly, the additional effect of debt in recessions appears to increase at longer horizons after the spending shock even though the uncertainty of the estimates is high, while the error bands overlap.
}

$$
I_{t}=\Delta G_{t}^{h m}-\Delta G_{t},
$$

where $\Delta G_{t}^{h m}$ and $\Delta G_{t}$ are government spending growth in potential high-multiplier $(\mathrm{hm})$ states and aggregate (national) growth in government spending in quarter $t$, respectively. Potential high-multiplier states are those that are in a (deep) recession at $t-1$ according to our business cycle indicators. ${ }^{24}$ An indicator $I_{t}$ that is positive hence implies extra redistribution of government spending of potential low-multiplier states to high-multiplier states relative to the level of government spending in the previous quarter, and vice versa when the indicator is negative. To check the robustness, we construct a similar indicator for redistribution toward states that have high household debt ratios. The latter are simply the top one-third of the states according to the average debt-to-GDP ratio over the whole sample.

Figure 8 shows the redistribution indicators. Overall, the indicators are quite volatile, which is not surprising since they are based on relative growth rates of spending. On average, the indicators based on the binary and continuous recession indicator are moderately negative: government spending growth was on average lower in states that were in a recession in the previous quarter. In contrast, government spending growth was on average slightly greater in states with higher household debt, whereas the indicator based on deep recessions is on average close to 0 . The latter indicator is also characterized by a big, negative shift in 2008 , followed by a large, positive spike in early 2009. The strong rise in 2009 reflects the ARRA spending program: government spending increased much more in states that had a deep recession. The correlation between the indicators turns out to be relatively low. For example, the correlation between the binary recession and household debt indicator is -0.09 , while the correlation between the continuous recession and deep recession indicator is 0.29 . This should be useful to assess the robustness of the results.

In the next step, we embed the indicators in a simple VAR model for the aggregate U.S. economy. Specifically, we estimate a three-variable VAR containing aggregate real government consumption and investment, the redistribution indicator, and aggregate real GDP. The VAR also includes a linear and quadratic trend and is estimated over the sample period 2005Q1 to 2015Q4 with four lags. Notice that the sample period is relatively short. The results should therefore be interpreted with caution, but should nevertheless provide useful insights on the macroeconomic effects of fiscal redistribution across states. Within this VAR model, we identify innovations to the index that are orthogonal to changes in aggregate government spending and estimate the macroconsequences. In line with the standard Blanchard and Perotti (2002) approach, we assume that the composition of government spending across state does not react within the quarter to

\footnotetext{
${ }^{24}$ To obtain $\Delta G_{t}^{h m}$, we weight the individual state growth rates by their share in total government spending.
} 

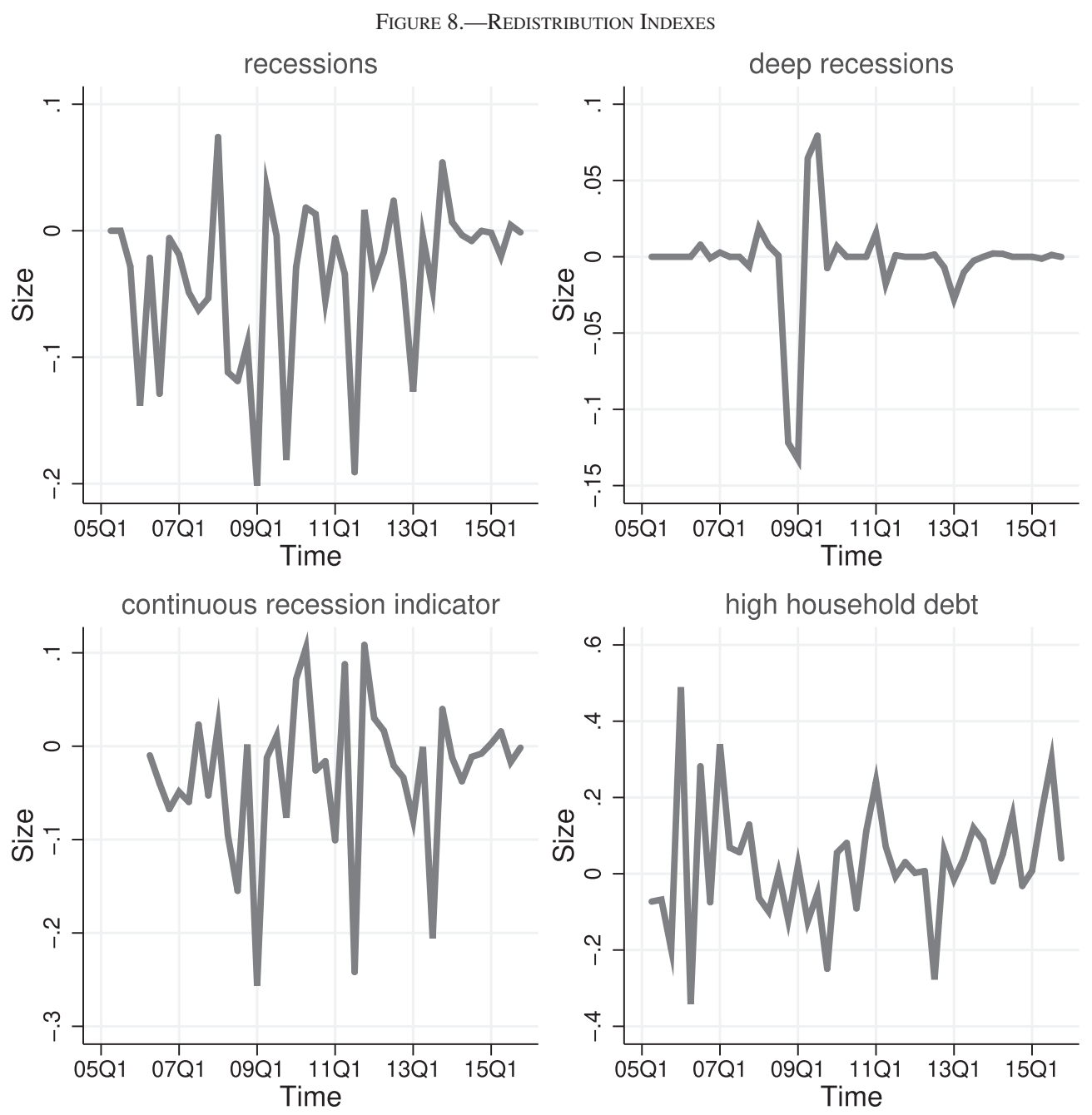

The green line shows the redistribution index applied to recessions, deep recessions, the continuous recession indicator, and household debt.

shocks to economic activity. This corresponds to a Cholesky decomposition with the variables ordered as described above.

The results of the estimations are reported in figure 9. The panels show the impulse responses to a 1 standard deviation innovation to the redistribution index, together with $68 \%$ and $90 \%$ confidence bands. For all four indicators, despite the relative low correlation, we find a significant impact of redistribution across states on aggregate economic activity. The effects are economically meaningful. Specifically, a 1-standard deviation increase in the redistribution index toward states in a (deep) recession or with high household debt levels augments aggregate GDP by approximately $0.2 \%$ to $0.4 \%$ after a few quarters. These estimates confirm that a regional redistribution of government expenditures across states is able to influence aggregate economic activity and may be a powerful tool to stimulate the economy.

\section{Conclusion}

Relative government spending multipliers are a key ingredient for policymakers who want to stabilize asymmetric shocks and divergent business cycles within a currency union. In this study, we have used a novel quarterly data set of U.S. states to estimate the dynamics of state relative government spending multipliers and their drivers over the period 2005Q1 to 2015Q4. The availability of quarterly data by state, along with a sizable cross-section dimension and variation in the data, allows for a detailed analysis of relative fiscal multipliers and their dependence on economic conditions in the period surrounding the Great Recession. Our benchmark estimations show an average relative cumulative multiplier of approximately 1.3 on impact, which remains stable at longer horizons after the fiscal stimulus. We also document moderate positive spillover effects of government spending on other states. The estimates should thus be seen as a lower bound of the effects on local activity.

In the next step, we have examined whether relative spending multipliers depended on some crucial underlying economic conditions of the states. These results reveal that impact multipliers were on average 1 when a state was in an expansion, in order to decrease at longer horizons. In contrast, we find that relative multipliers were more persistent 
Figure 9.-Aggregate EfFects of Redistribution Shocks

(a) redistribution of spending to US states in recessions

aggregate government spending

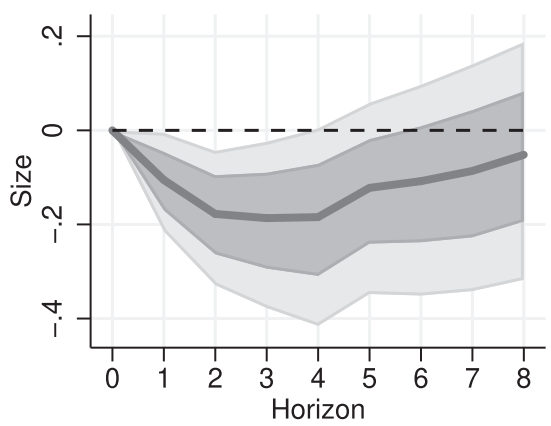

redistribution index (recessions)

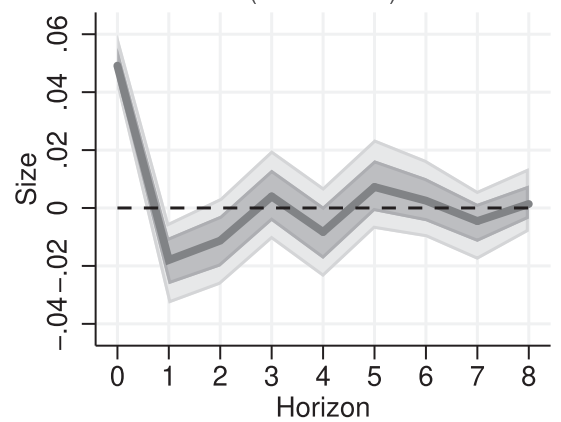

aggregate GDP

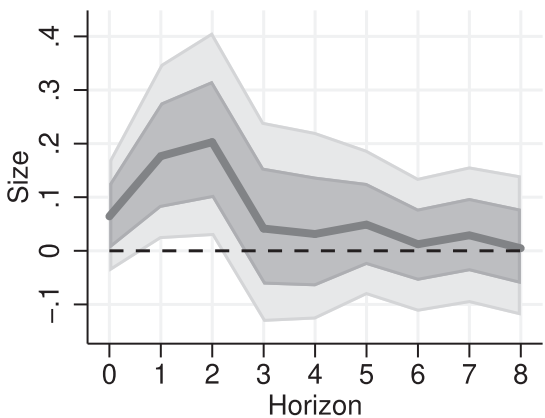

(b) redistribution of spending to US states in deep recessions

aggregate government spending

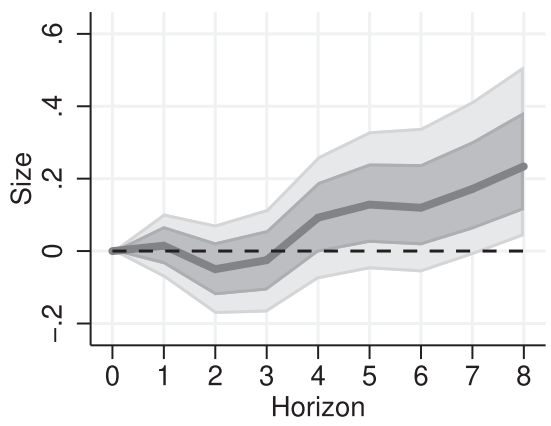

redistribution index (deep recessions)

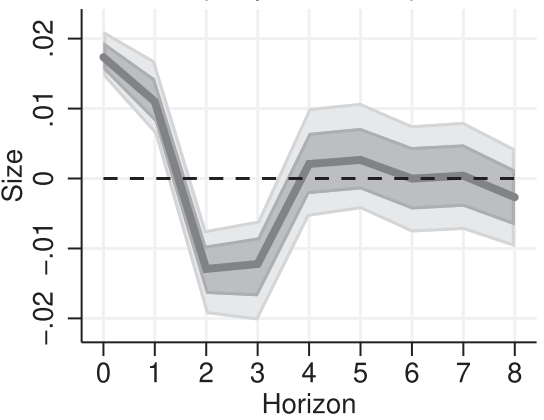

aggregate GDP

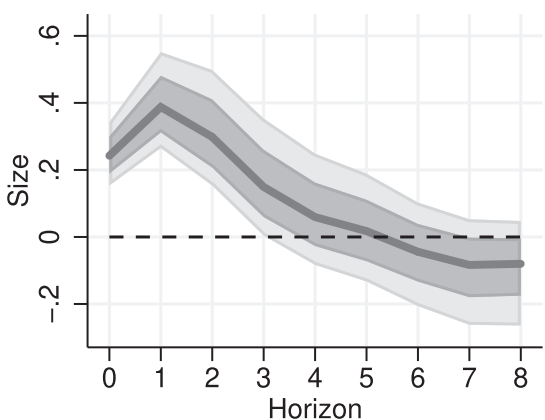

(c) redistribution of spending to US states in recessions (continuous indicator)

aggregate government spending

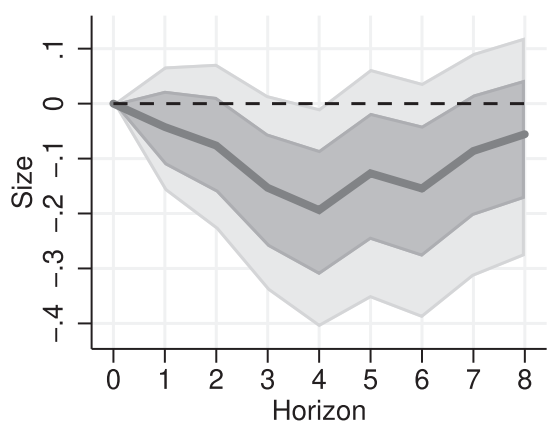

redistribution index (continuous recession indicator)

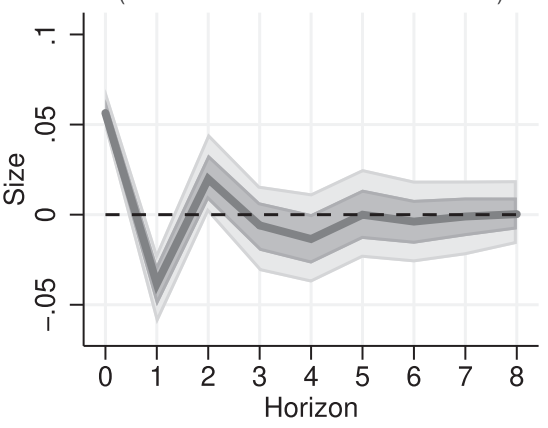

aggregate GDP

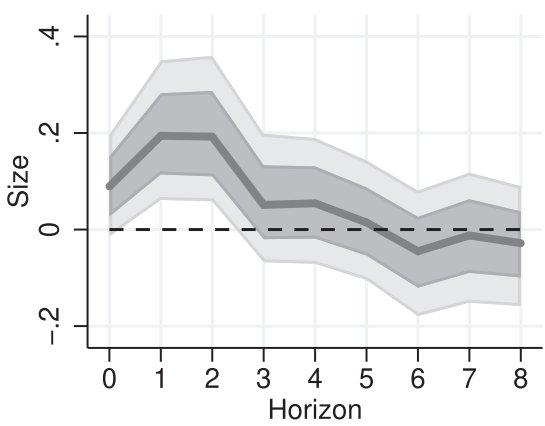

(d) redistribution of spending to US states with high household debt
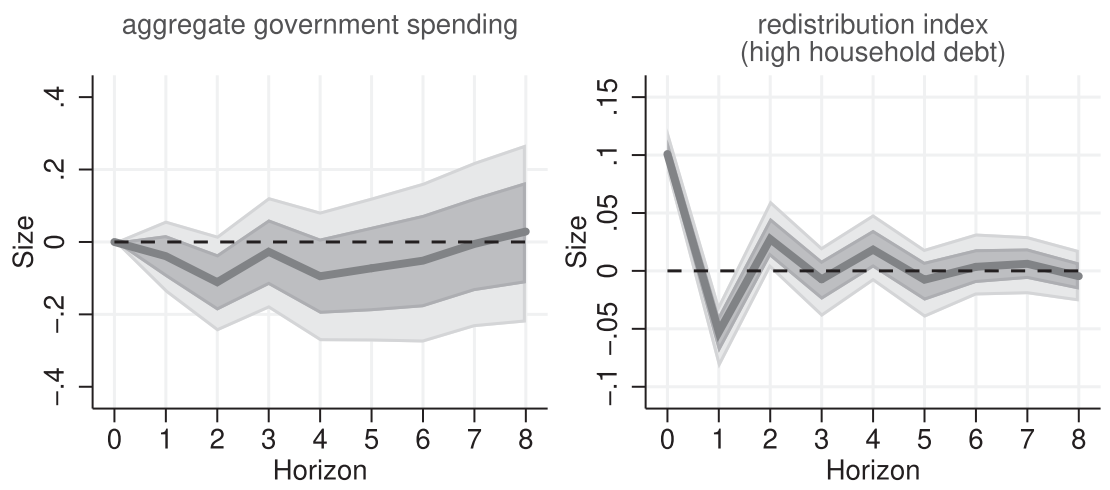

aggregate GDP

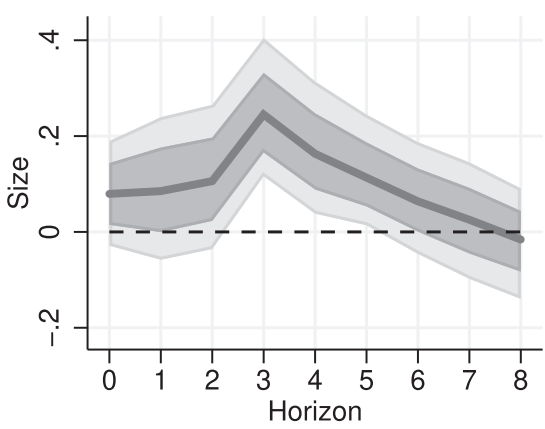

Bands are 68\% (dark) and 90\% (light) confidence intervals. The redistribution shock is normalized to 1-standard deviation. 
and (considerably) larger when a state was in a (severe) recession at the moment of the fiscal impulse, reaching values above 4 . In addition, multipliers increased by the state's amount of private debt. The latter effect on multipliers was even more the case in recessionary periods: states that were characterized by high household indebtness had a rise in their multiplier by roughly 2 when their economy was in a slump. The influence of these conditions on relative multipliers is hence economically important and should be taken into account by policymakers in practice.

A lesson that we could also learn from the estimations is that mere targeted redistributions of government spending across states may also stimulate aggregate U.S. economic activity. This can be done by redistributing government expenditures from states with low relative multipliers to states with large multipliers. By constructing a simple redistribution index, we provide evidence that implicit redistribution of government spending within the sample period had sizable aggregate effects. This finding is a promising avenue for a more detailed analysis in future research.

\section{REFERENCES}

Albuquerque, Bruno, "One Size Fits All? Monetary Policy and Asymmetric Household Debt Cycles in US States," Ghent University manuscript (2017).

Andrés, Javier, José E. Boscá, and Javier Ferri, "Household Debt and Fiscal Multipliers," Economica 82 (2015), 1048-1081.

Auerbach, Alan. J., and Yuriy Gorodnichenko, "Fiscal Multipliers in Recession and Expansion" (pp. 63-98), in A. Alesina and F. Giavazzi eds., Fiscal Policy after the Financial Crisis (Chicago: University of Chicago Press, 2012a).

"Measuring the Output Responses to Fiscal Policy," American Economic Journal: Economic Policy 4:2 (2012b), 1-27.

"Output Spillovers from Fiscal Policy," American Economic Review Papers and Proceedings 103:3 (2013), 141-146.

Baker, Scott R., "Debt and the Response to Household Income Shocks: Validation and Application of Linked Financial Account Data," Journal of Political Economy 126 (2018), 1504-1557.

Bartik, Timothy J., "Who Benefits from State and Local Economic Development Policies?" (Kalamazoo, MI: W. E. Upjohn Institute for Employment Research, 1991).

Bernanke, Ben, and Mark Gertler, "Agency Costs, Net Worth, and Business Fluctuations," American Economic Review 79 (1989), 14-31.

Bernardini, Marco, and Gert Peersman, "Private Debt Overhang and the Government Spending Multiplier: Evidence for the United States," Journal of Applied Econometrics 33 (2018), 485-508.

Blanchard, Olivier J., and Daniel Leigh, "Growth Forecast Errors and Fiscal Multipliers," American Economic Review: Papers and Proceedings 103 (2013), 117-120.

Blanchard, Olivier J., and Roberto Perotti, "An Empirical Characterization of the Dynamic Effects of Changes in Government Spending and Taxes on Output," Quarterly Journal of Economics 117 (2002), 1329-1368.

Bohn, Henning, and Robert P. Inman, "Balanced-Budget Rules and Public Deficits: Evidence from the U.S. States," Carnegie-Rochester Conference Series on Public Policy 45:1 (1996), 13-76.

Brückner, Markus, and Anita Tuladhar, "Local Government Spending Multipliers and Financial Distress: Evidence from Japanese Prefectures," Economic Journal 124 (2014), 1279-1316.

Caggiano, Giovanni, Efrem Castelnuovo, Valentina Colombo, and Gabriela Nodari, "Estimating Fiscal Multipliers: News from a Non-Linear World," Economic Journal 125 (2015), 746-776.

Canzoneri, Matthew, Fabrice Collard, Harris Dellas, and Behzad Diba, "Fiscal Multipliers in Recessions," Economic Journal 126 (2016), 75108.

Cashin, David, Jamie Lenney, Byron Lutz, and William Peterman, "Fiscal Policy and Aggregate Demand in the U.S. before, during and follow- ing the Great Recession," Finance and Economics discussion series 2017-061 working paper (2017).

Chodorow-Reich, Gabriel, Laura Feiveson, Zachary Liscow, and William Gui Woolston, "Does State Fiscal Relief during Recessions Increase Employment? Evidence from the American Recovery and Reinvestment Act," American Economic Journal: Economic Policy 4:3 (2012), 118-145.

Christiano, Lawrence, Martin Eichenbaum, and Sergio Rebelo, "When Is the Government Spending Multiplier Large?" Journal of Political Economy 119:1 (2011), 78-121.

Cloyne, James S., and Paolo Surico, "Household Debt and the Dynamic Effects of Income Tax Changes," Review of Economic Studies 84 (2017), 45-81.

Cochrane, John H., "Manna from Heaven: The Harvard Stimulus Debates," Grumpy Economist (blog) March 4, 2012.

Costello, Anna M., Reining Petacchi, and Joseph P. Weber, "The Impact of Balanced Budget Restrictions on States' Fiscal Actions," Accounting Review 92:1 (2017), 51-71.

Delong, J. Bradford, and Lawrence H. Summers, "Fiscal Policy in a Depressed Economy," Brookings Papers on Economic Activity 43 (2012), 233-297.

Demyanyk, Yuliya, Elena Loutskina, and Daniel Murphy, "Fiscal Stimulus and Consumer Debt," Federal Reserve Bank of Cleveland working paper 16-20 (2016).

Driscoll, John C., and Aart C. Kraay, "Consistent Covariance Matrix Estimation with Spatially Dependent Panel Data," this REVIEW 80 (1998), 549-560.

Dupor, Bill, and Rodrigo Guerrero, "Local and Aggregate Fiscal Policy Multipliers," Journal of Monetary Economics 92 (2017), 16-30.

Eggertsson, Gauti B., and Paul Krugman, "Debt, Deleveraging, and the Liquidity Trap: A Fisher-Minsky-Koo Approach," Quarterly Journal of Economics 127 (2012), 1469-1513.

Fazzari, Steven M., James Morley, and Irina Panovska, "State-Dependent Effects of Fiscal Policy," Studies in Nonlinear Dynamics and Econometrics 19 (2015), 285-315.

Gordon, Robert J., and Robert Krenn, "The End of the Great Depression, 1939-41: Policy Contributions and Fiscal Multipliers," NBER working paper 16380 (2010).

Hall, Robert E., "By How Much Does GDP Rise If the Government Buys More Output?" Brookings Papers on Economic Activity 40 (2009), 183-249.

Jordà, Òscar, "Estimation and Inference of Impulse Responses by Local Projections," American Economic Review 95 (2005), 161-182.

Jordà, Òscar, and Alan M. Taylor, "The Time for Austerity: Estimating the Average Treatment Effect of Fiscal Policy," Economic Journal, 126 (2016), 219-255.

Kaplan, Greg, and Giovanni L. Violante, "A Model of the Consumption Response to Fiscal Stimulus Payments," Econometrica 82 (2014), 1199-1239.

Kaplan, Greg, Giovanni L. Violante, and Justin Weidner, "The Wealthy Hand-to-Mouth," Brookings Papers on Economic Activity 45 (2014), $77-153$.

Klein, Mathias, “Austerity and Private Debt," Journal of Money, Credit and Banking 49 (2017), 1555-1585.

Mian, Atif, and Amir Sufi, "Household Leverage and the Recession of 2007-09," IMF Economic Review 58 (2010), 74-117.

Michaillat, Pascal, "A Theory of Countercyclical Government Multiplier," American Economic Journal: Macroeconomics 6 (2014), 190-217.

Misra, Kanishka, and Paolo Surico, "Consumption, Income Changes, and Heterogeneity: Evidence from Two Fiscal Stimulus Programs," American Economic Journal: Macroeconomics 6 (2014), 84106.

Montiel Olea, José Luis, and Carolin Pflueger, “A Robust Test for Weak Instruments," Journal of Business and Economic Statistics 31 (2013), 358-369.

Nakamura, Emi, and Jón Steinsson, "Fiscal Stimulus in a Monetary Union: Evidence from US Regions," American Economic Review 104 (2014), 753-792.

Ozer Balli, Hatice, and Bent E. Sørensen, "Interaction Effects in Econometrics," B.E. Empirical Economics 45 (2013), 583-603.

Peersman, Gert, and Frank Smets, "The Industry Effects of Monetary Policy in the Euro Area," Economic Journal 115 (2005), 319-342.

Perotti, Roberto, "Fiscal Policy in Good Times and Bad," Quarterly Journal of Economics 114 (1999), 1399-1436. 
Poterba, James M., "State Responses to Fiscal Crises: The Effects of Budgetary Institutions and Politics," Journal of Political Economy 102 (1994), 799-821.

Ramey, Valerie A., "Identifying Government Spending Shocks: It's All in the Timing," Quarterly Journal of Economics 126 (2011a), 1-50.

"Can Government Purchases Stimulate the Economy?" Journal of Economic Literature 49 (2011b), 673-685.

"Government Spending and Private Activity" (pp. 19-55), in A. Alesina and F. Giavazzi, eds., Fiscal Policy after the Financial Crisis (Chicago: University of Chicago Press, 2013).

"Macroeconomic Shocks and Their Propagation" (pp. 71-162), in J. B. Taylor and H. Uhlig, eds., Handbook of Macroeconomics, vol. 2 (Amsterdam: Elsevier, 2016)

Ramey, Valerie A., and Sarah Zubairy, "Government Spending Multipliers in Good Times and in Bad: Evidence from U.S. Historical Data," Journal of Political Economy 126 (2018), 850-901.

Sahm, Claudia R., Matthew D. Shapiro, and Joel Slemrod, "Balance-Sheet Households and Fiscal Stimulus: Lessons from the Payroll Tax Cut and Its Expiration," NBER working paper 21220 (2015).

Serrato, Juan Carlos Suárez and Philippe Wingender, "Estimating Local Fiscal Multipliers," NBER working paper 22425 (2016).

Shoag, Daniel, "Using State Pension Shocks to Estimate Fiscal Multipliers since the Great Recession," American Economic Review: Papers and Proceedings 103 (2013), 121-124.

\section{Data Appendix}

- GDP by state and industry (U.S. Bureau of Economic Analysis). The original series are quarterly, expressed in millions of dollars and seasonally adjusted at annual rates. State-level GDP is "All Industry Total," while statelevel government spending is "Government." The nominal GDP series are deflated by state-level GDP deflators, the government spending series by state-level government spending deflators.

- Personal income by state (U.S. Bureau of Economic Analysis). The original series are quarterly, expressed in thousands of dollars and seasonally adjusted at annual rates.

- Household debt by state (Federal Reserve Bank of New York). The original series report the stock of household mortgage debt in the last quarter of the year $(\mathrm{Q} 4)$ and are expressed in dollars. We compute state-level debt-toincome ratios by dividing the original series by personal income. Since consumer debt evolves slowly, we use linear interpolation to impute the missing values in order to have quarterly series.

- Trade partners by state (U.S. Census Bureau 2007 Commodity Flow Survey). Trade partners of state $i$ are ranked according to their importance in bilateral trade of state $i$. The strength of bilateral trade between state $i$ and state $j$ is based on the 2007 total value of commodities that flow from state $i$ to $j$, divided by nominal government spending in state $j$ (averaged over 2007). A state's major trade partner is defined as the state that receives the largest amount of (nominal) exports from state $i$ relative to that partner state's (nominal) government spending. A state's least important trade partner is defined as the state that receives the smallest amount of exports. ${ }^{25}$ Trade-weighted sums for state i are calculated based on constant weights of each partner state $j$ capturing nominal exports to state $j$ of state $i$ relative to government spending in state $j$. These weights are scaled to sum up to 1 over all states other than $i$. The Commodity Flow Survey was conducted five times between 1993 and 2012. We use the 2007 data because these are closest to the beginning of the sample under analysis and we assume that the trade weights are representative for the trade linkages throughout the entire time period.

- U.S. aggregate data. All data are retrieved from FRED, Federal Reserve Bank of St. Louis.

\footnotetext{
${ }^{25}$ Given that there are missing values and 0 s for some states, we have the additional criterion that in case of multiple 0 s, we take that state among the several states with a 0 share for which the most important trade partner of $i$ shows the lowest trade share. This is based on an indirect trade argument.
} 